\title{
Glutathione disulfide induces neural cell death via a 12-lipoxygenase pathway
}

\author{
H-A Park ${ }^{1}$, S Khanna ${ }^{1}$, C Rink ${ }^{1}$, S Gnyawali ${ }^{1}$, S Roy ${ }^{1}$ and CK Sen ${ }^{*, 1}$
}

Oxidized glutathione (GSSG) is commonly viewed as a byproduct of GSH metabolism. The pathophysiological significance of GSSG per se remains poorly understood. Adopting a microinjection approach to isolate GSSG elevation within the cell, this work identifies that GSSG can trigger neural HT4 cell death via a 12-lipoxygenase (12-Lox)-dependent mechanism. In vivo, stereotaxic injection of GSSG into the brain caused lesion in wild-type mice but less so in 12-Lox knockout mice. Microinjection of graded amounts identified $0.5 \mathrm{mM}$ as the lethal [GSSG]i in resting cells. Interestingly, this threshold was shifted to the left by 20-fold $(0.025 \mathrm{mM})$ in GSH-deficient cells. This is important because tissue GSH lowering is commonly noted in the context of several diseases as well as in aging. Inhibition of GSSG reductase by BCNU is known to result in GSSG accumulation and caused cell death in a 12-Lox-sensitive manner. GSSG S-glutathionylated purified 12-Lox as well as in a model of glutamate-induced HT4 cell death in vitro where V5-tagged 12-Lox was expressed in cells. Countering glutamate-induced 12-Lox S-glutathionylation by glutaredoxin-1 overexpression protected against cell death. Strategies directed at improving or arresting cellular GSSG clearance may be effective in minimizing oxidative stress-related tissue injury or potentiating the killing of tumor cells, respectively.

Cell Death and Differentiation (2009) 16, 1167-1179; doi:10.1038/cdd.2009.37; published online 17 April 2009

Free glutathione, a tripeptide with the sequence $\gamma$-Glu-CysGly, exists either in a reduced form with a free thiol group (GSH) or in an oxidized form with a disulfide between two identical molecules (GSSG). GSH is a ubiquitous low molecular weight intracellular thiol present in all aerobic cells in millimolar concentrations. The sulfhydryl (-SH) group supports the reducing properties of GSH by way of a thiolexchange system (-SH to -S-S-), making GSH one of the most abundant and powerful intracellular antioxidants. Besides scavenging free radicals and reactive oxygen species, GSH detoxifies tissues by conjugating with various electrophiles including xenobiotics. In addition, GSH serves as a major reservoir of cysteine for cellular protein synthesis.

Under basal conditions, GSSG represents $1 \%$ of the total GSH in the cell. ${ }^{1}$ Under conditions of oxidant insult, GSH is rapidly oxidized to GSSG. Thus, an elevated GSSG/GSH ratio is often used as a marker for oxidative stress. ${ }^{2}$ Cellular GSSG may be recycled to $\mathrm{GSH}$ in the presence of reductases such as NADPH-dependent GSSG reductase. Excessive GSSG, as generated during sudden oxidant insult, is pumped out of the cell by a ATP-dependent process underscoring the urgent need of the cell to protect itself from a GSSG surge. . $^{3,4}$ In most studies, GSSG is dealt with as a byproduct of GSH metabolism. As cellular GSH concentration is expected to be in the range of $1-5 \mathrm{mM}$, millimolar concentrations of GSSG are expected in cells under conditions of oxidant insult. However, knowledge about the potential biological signifi- cance of GSSG per se is limited. Although excessive oxidant insult causes necrotic cell death, a more moderate challenge triggers secondary responses in the cell that culminate in cell death. Elevation in cellular GSSG levels represents one such rapid cellular response to moderate oxidant insult. In this study, we sought to examine whether elevated cellular GSSG levels may directly influence cell death. Addressing this question would require that cellular GSSG elevation be isolated from all other biological causative factors. Thus, we adopted the microinjection approach ${ }^{5}$ to raise cellular GSSG or GSH as control to investigate the significance of GSSG on cell death. To test the significance of our findings in vitro, GSSG was stereotaxically injected to the brain in vivo and magnetic resonance imaging (MRI) was performed to quantify tissue lesion.

\section{Results \\ Increased extracellular glutamate depletes intracellular GSH. ${ }^{6}$ To test the significance of this loss of cellular GSH during glutamate-induced loss of HT4 cell viability, GSH was replenished in glutamate-treated cells by microinjection. Previously we have reported that $4 \mathrm{~h}$ of glutamate treatment markedly depletes the cellular GSH pool. ${ }^{6,7}$ Thus, $4 \mathrm{~h}$ gluta- mate treatment was performed in these experiments. After $4 \mathrm{~h}$ of treatment, glutamate was withdrawn and cell were microinjected with GSH. As the antioxidant properties of GSH}

\footnotetext{
${ }^{1}$ Department of Surgery, Davis Heart and Lung Research Institute, The Ohio State University Medical Center, Columbus, OH, USA

${ }^{*}$ Corresponding author: CK Sen, Department of Surgery, 512 Davis Heart and Lung Research Institute, 473 West 12th Avenue, The Ohio State University Medical Center, Columbus, OH 43210, USA. Tel: + 614247 7658; Fax: + 614247 7818; E-mail: chandan.sen@ osumc.edu

Keywords: thiol; stroke; vitamin E; neurodegeneration; redox; antioxidant

Abbreviations: 12-Lox, 12-lipoxygenase; BCNU, 1,3-bis(2-chloroethyl)-1-nitrosourea; BL-15, 5,6,7,-trihydroxyflavone; BSO, L-buthioninesulfoximine; GRx1, glutaredoxin-1; GSH, reduced glutathione; GSSG, glutathione disulfide; LDH, lactate dehydrogenase; MCA, middle cerebral artery; PMPI, plasma membrane potential indicator; TCT, $\alpha$-tocotrienol; TMRM, tetramethylrhodamine methyl ester

Received 30.9.08; revised 20.2.09; accepted 02.3.09; Edited by JA Cidlowski ; published online 17.4.09
} 
were being tested, GSSG was selected as control. As control for GSH injection, GSSG injection was performed. GSH microinjection did not significantly rescue cells from glutamateinduced death. This observation was consistent with our previous indirect observation that glutathione depletion is not critically important in causing cell death because we were previously able to afford complete protection by the $\alpha$-tocotrienol form of natural vitamin $E$ under conditions where glutamate-induced glutathione loss remained unaffected. ${ }^{6}$ Of striking interest, however, was the observation that the control cells microinjected with GSSG were all lost to death. GSSG microinjection proved to be potently cytotoxic (Figure 1). This serendipitous observation led us to examine the threshold of intracellular GSSG concentration ([GSSG]i) that triggers cell death of HT4 neural cells. Based on atomic force microscopy measurements, we determined that the mean $\mathrm{HT} 4$ cell volume is in the order of $1 \mathrm{pl}$ (not shown). Microinjection of graded amounts of GSSG was performed to identify the threshold concentration of GSSG that trigger cell death. It was noted that injection of 500 attomoles of GSSG, which is equivalent to $0.5 \mathrm{mM}$ of [GSSG]i, was the threshold at which GSSG caused death of HT4 cell under standard culture conditions (Figure 2a). Under conditions of glutamate challenge or other insult leading to cell death, cellular GSH levels are known to fall sharply. ${ }^{6}$ Therefore, we chose to lower GSH levels in cells by arresting GSH synthesis using BSO. BSO sharply increased GSSG levels (Figure 2c) and depleted cellular GSH pool by $80 \%$ (Figure 2d), similar to the magnitude noted during glutamate challenge. ${ }^{6}$ Under such GSH-depleted conditions, HT4 cells were noted to become more sensitive to GSSG-induced cell
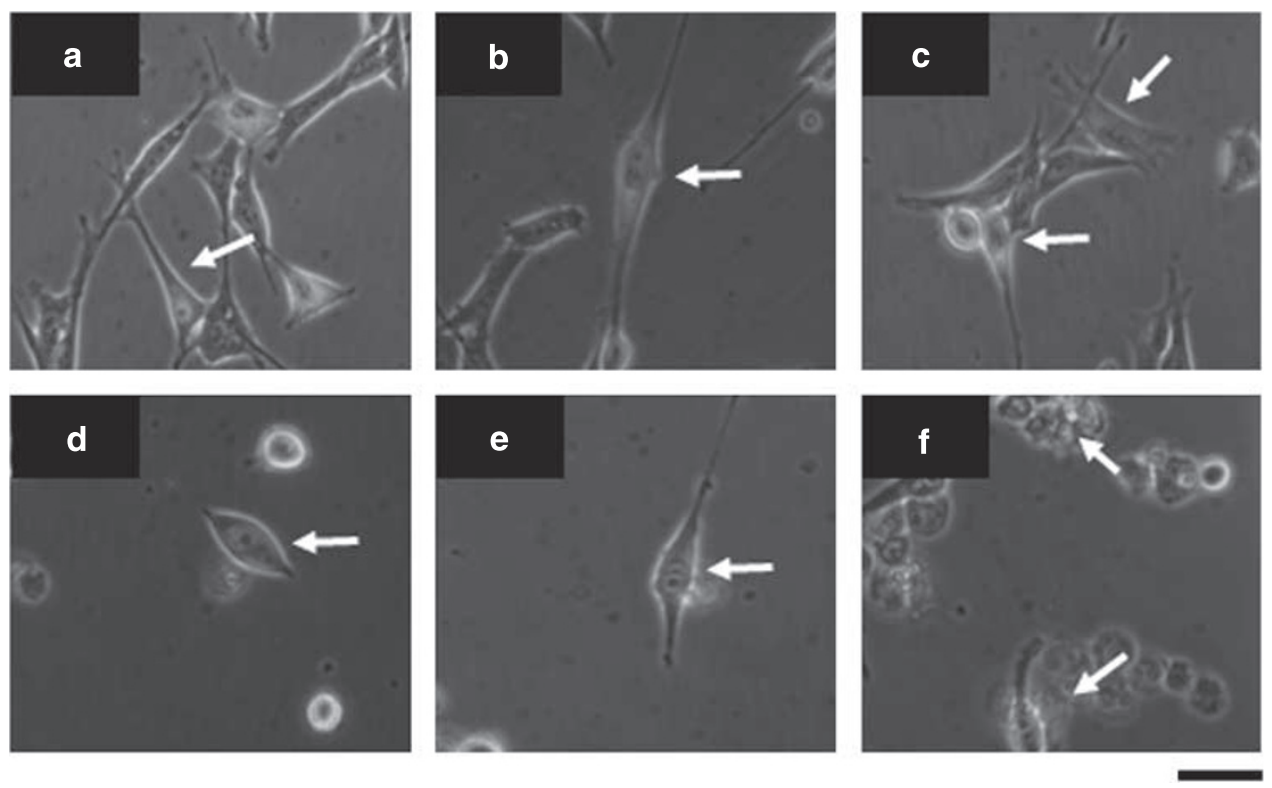

g

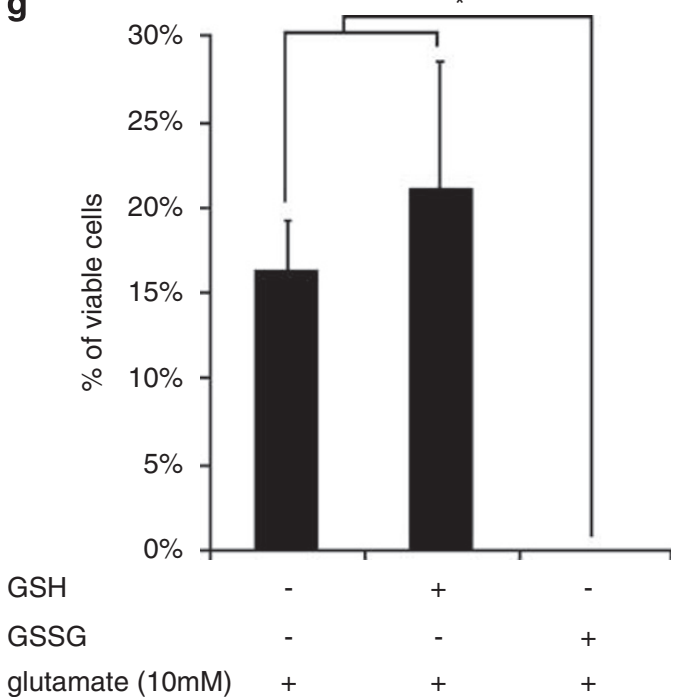

Figure 1 Microinjected GSH failed to rescue, whereas GSSG potentiated glutamate-induced death of HT4 neural cells. PBS (a), 500 attomole GSH (b), or GSSG (c) was injected into the cytoplasm after $4 \mathrm{~h}$ glutamate challenge. After $24 \mathrm{~h}$ incubation, some (15-20\%) HT4 cells injected with PBS (d) or GSH (e) remained alive, whereas all GSSGinjected cells (f) were dead (g) suggesting GSSG toxicity. Attomoles injected [micromolar]i, $n=3$, Bar, $20 \mu \mathrm{m}$. *Lower than control. Results are mean \pm S.D. ${ }^{*} P<0.05$ 

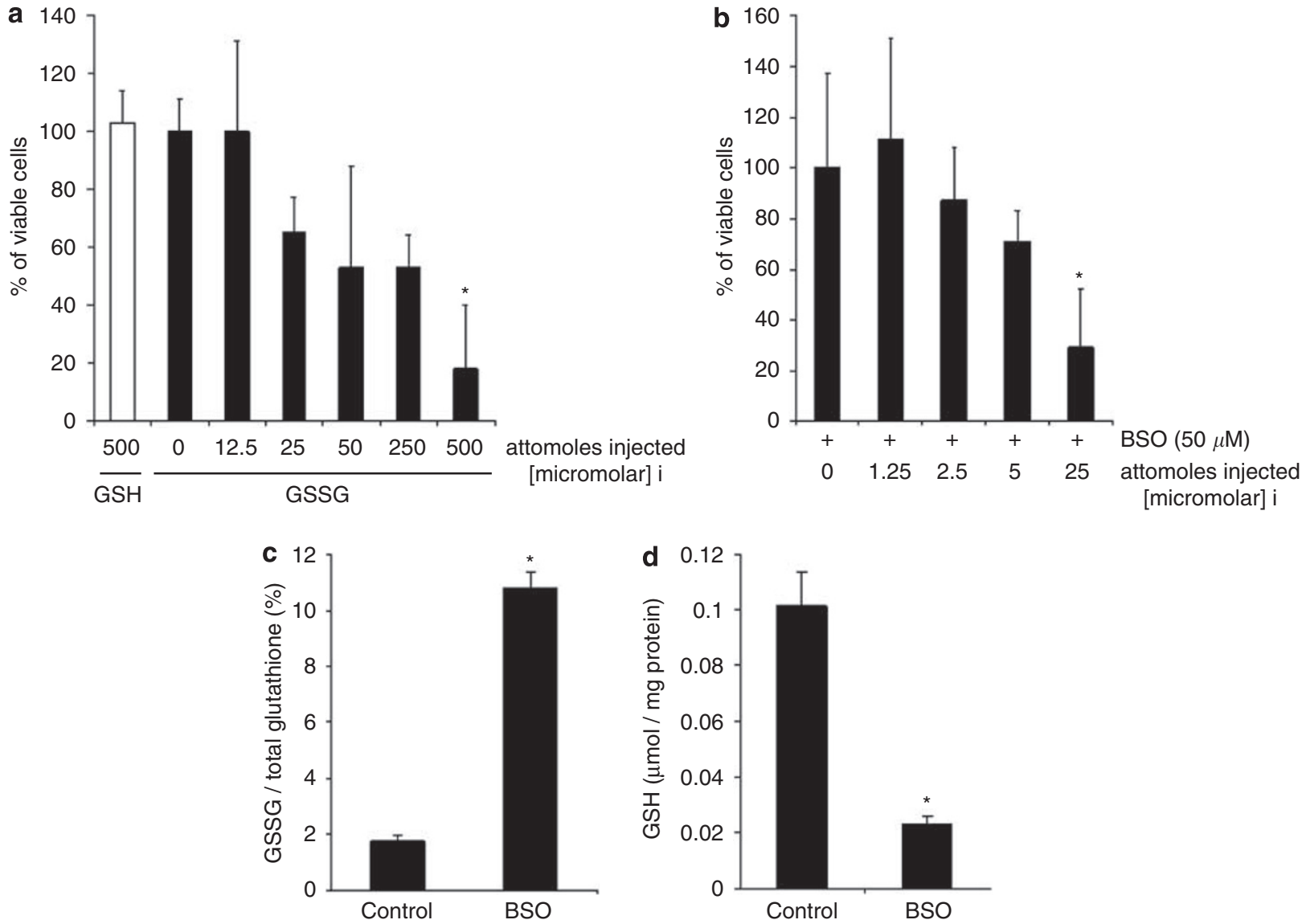

Figure 2 Dose-dependent GSSG toxicity. (a) 500 attomole GSH or GSSG $(0,12.5,25,50,250$, and 500 attomoles) was microinjected into the cytoplasm of HT4 cells for $24 \mathrm{~h}$. (b) GSSG $(0,1.25,2.5,5$ and 25 attomoles) was injected into the cytoplasm of HT4 cells pretreated with $50 \mu \mathrm{M} \mathrm{BSO}$ for $12 \mathrm{~h}$. Cellular GSSG/total glutathione (c) was increased, and absolute value of GSH ( $\mu \mathrm{mol} / \mathrm{mg}$ protein) was decreased after $50 \mu \mathrm{M}$ BSO treatment (d). Attomoles injected [micromolar]i, $n=3$, Results are mean \pm S.D. ${ }^{*} P<0.05$

death. In such GSH-deficient cells, the threshold for GSSGinduced lethality was lowered by 20 -fold such that microinjection of 25 attomoles (corresponding to $0.025 \mathrm{mM}$ ) of GSSG caused cytotoxicity (Figure $2 b-d$ ). These observations underscore the heightened significance of GSSG as an inducer of cell death under conditions of GSH depletion.

Characterization of GSSG-induced death of HT4 neural cells was started by testing the involvement of mitochondrial dysfunction as is commonly associated with cell death. Cytosolic injection of GSSG was observed to selectively compromise mitochondrial membrane potential although not affecting plasma membrane potential (Figure 3). Previously, we had reported that GSH-depletion in glutamate-challenged HT4 neural cells leads to the activation of 12-lipoxygenase, which is central in executing glutamate-induced neural cell death. Inhibitors of 12-lipoxygenase, including BL-15 and $\alpha$-tocotrienol, prevent glutamate-induced HT4 cell death. ${ }^{5,6,8,9}$ We therefore sought to examine whether GSSG-induced death of HT4 neural cells is mediated by 12-lipoxygenae. Both inhibitors of 12 -lipoxygenase, BL-15 as well as $\alpha$-tocotrienol, significantly protected against GSSG-induced loss of cell viability suggesting the involvement of 12-lipoxygenase in this death pathway (Figure 4). Next, we utilized the advantages of the microinjection approach to test the significance of 12-lipoxygenase and its substrate arachidonic acid in the death of GSH-deficient HT4 cells. Although depletion of cellular GSH reserves by arresting GSH synthesis using BSO does not cause cell death, such GSH-deficient cells are known to be highly sensitive to extracellular arachidonic acid treatment. ${ }^{9}$ Consistently, in this study we observed that microinjection of small amounts of free arachidonic acid to GSH-deficient HT4 cells caused cell death (Figure 5). Both $\mathrm{BL}-15$ as well as $\alpha$-tocotrienol protected against such death suggesting the involvement of 12-lipoxygenase in intracellular free arachidonic acid-induced cell death. Supporting this conclusion is our observation that direct administration of active 12-lipoxygenase into GSH-deficient cells causes cell death in a BL-15 and $\alpha$-tocotrienol-sensitive manner (Figure 5). Next, we sought to test whether endogenous GSSG may kill cells by a 12-lipoxygenase-dependent mechanism. BCNU, a well-characterized specific GSSG reductase inhibitor, was chosen as a pharmacological tool to increase cellular GSSG/GSH ratio. ${ }^{10,11}$ Indeed, BCNUinduced elevation of cellular GSSG caused cell death. BCNU-induced cell death was significantly lowered by $\mathrm{BL}-15$ as well as $\alpha$-tocotrienol suggesting the involvement of 12-lipoxygenase (Figure 6a-f). Inhibition of GSSG efflux by MK-571, a specific inhibitor for multidrug resistance 

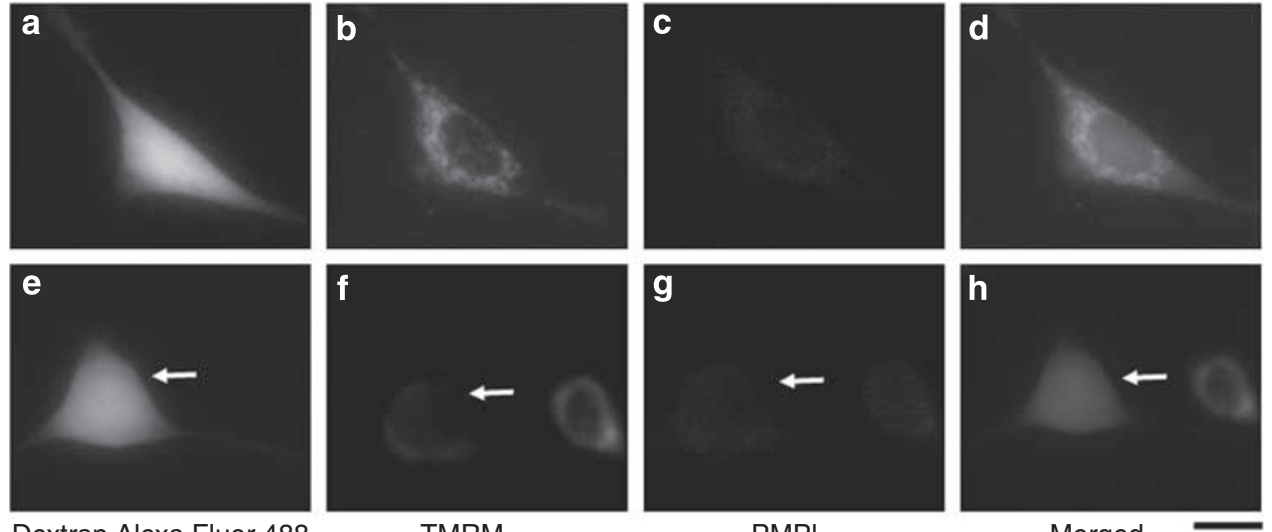

Dextran Alexa Fluor 488

TMRM

PMPI

Merged

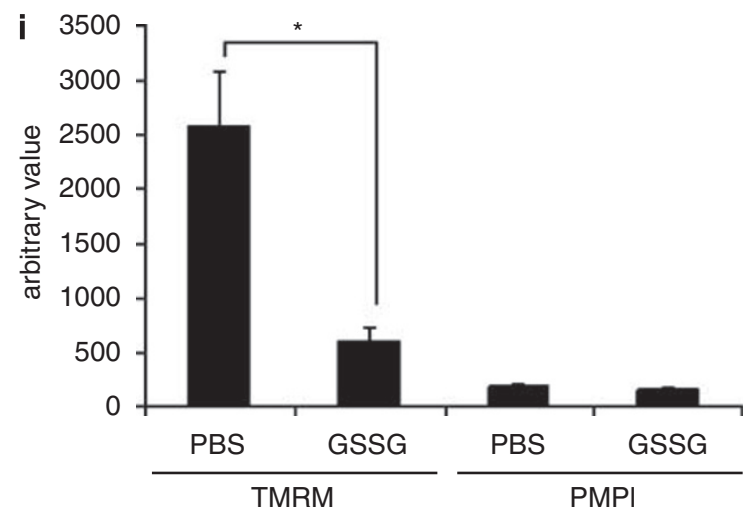

Figure 3 Cytosolic injection of GSSG compromised mitochondrial membrane potential. HT4 cells were injected with either PBS ((a) Dextran alexa fluor 488; (b) 8 nM TMRM; (c) $0.5 \mu \mathrm{l} / \mathrm{ml} \mathrm{PMPI;} \mathrm{(d)} \mathrm{merged} \mathrm{image)} \mathrm{or} 500$ attomole GSSG ((e) Dextran alexa fluor 488; (f) $8 \mathrm{nM} \mathrm{TMRM;} \mathrm{(g)} 0.5 \mu / / \mathrm{ml} \mathrm{PMPI;} \mathrm{(h)} \mathrm{merged} \mathrm{image).} \mathrm{Dextran} \mathrm{alexa} \mathrm{fluor}$ 488 was coinjected to visualize injected cells. After $2 \mathrm{~h}$ incubation, $8 \mathrm{nM}$ TMRM and $0.5 \mu / \mathrm{ml} \mathrm{PMPI}$ were treated to cell culture medium. (i) GSSG-injected cells showed lower mitochondrial membrane potential (f) compared to sham-injected cells (b) whereas plasma membrane potential was not affected (c and $\mathbf{g}$ ). Attomoles injected [micromolar], $n=3$, Bar, $30 \mu \mathrm{m}$. Results are mean \pm S.D. ${ }^{*} P<0.05$

protein-1 (MRP1) ${ }^{12,13}$ significantly increased loss of HT4 viability (Figure 6g).

Consistent observations indicating that GSSG may induce cell death by a 12-lipoxygenase-dependent mechanism led us to investigate the relationship between GSSG and 12-lipoxygenase. Using a standard assay to measure 12-lipoxygenase activity it was noted that the presence of GSSG in the reaction mixture significantly increases the catalytic function of 12-lipoxygenase (Figure 7a). GSSG was noted to cause marked $S$-glutathionylation of proteins in HT4 cells (Figure 7b). Control cells did show baseline glutathionylation levels (Supplementary Figure S1) but they are not noticed in Figure $7 \mathrm{~b}$ because film exposure time was minimized to obtain a good resolution blot of the GSSG treated cells. Signal detected as protein glutathionylation by immunoblots was reversed under reducing conditions demonstrating specificity of the antibody used (Supplementary Figure S1). To determine whether 12-lipoxygenase is subject to GSSG-induced S-glutathionylation HT4 cells were transfected with vectors expressing V5-tagged 12-lipoxygenase. Cell lysates from such cells, containing V5-tagged 12-lipoxygenase, were incubated with GSSG. Interestingly, the formation of GSS-12-lipoxygenase was noted (Figure 7c). Thus, GSSG is capable of $S$-glutathionylating 12-lipoxygenase. These findings were consistent with our observation that GSSG is able to $S$-glutathionylate pure 12-lipoxygenase obtained commercially (Figure 7d).

Glutaredoxin-1(GRx1) is the most specific and efficient deglutathionylating enzyme in the cytoplasm of mammalian cells. ${ }^{14}$ To test the overall significance of $S$-glutathionylation on glutamate-induced cell death, HT4 cells were infected with an adenoviral vector expressing GRx1. The gene delivery process was successful in markedly increasing cellular GRx1 expression (Figure 8a-c). Globally, GRx1 overexpression lowered the empirical abundance of $S$-glutathionylated proteins in the cell indicating elevated catalytic function of GRx1 in the cells (Figure 8d). Overexpression of GRx1 significantly protected HT4 neural cells against glutamate challenge. These findings suggest the involvement of $S$-glutathionylation reactions in glutamate-induced cell death (Figure 8e). To expand on the mechanism by which GRx1 may have protected the cells against glutamate insult, $S$-glutathionylation of V5-tagged 12-lipoxygenase was examined in HT4 cells. Glutamate increased 12-lipoxygenase glutanthionylation, which was prevented in GRx1 overexpressing cells (Figure 8f). These findings were consistent with results from studies employing the microinjection approach demonstrating that cytosolic delivery GRx1 significantly 

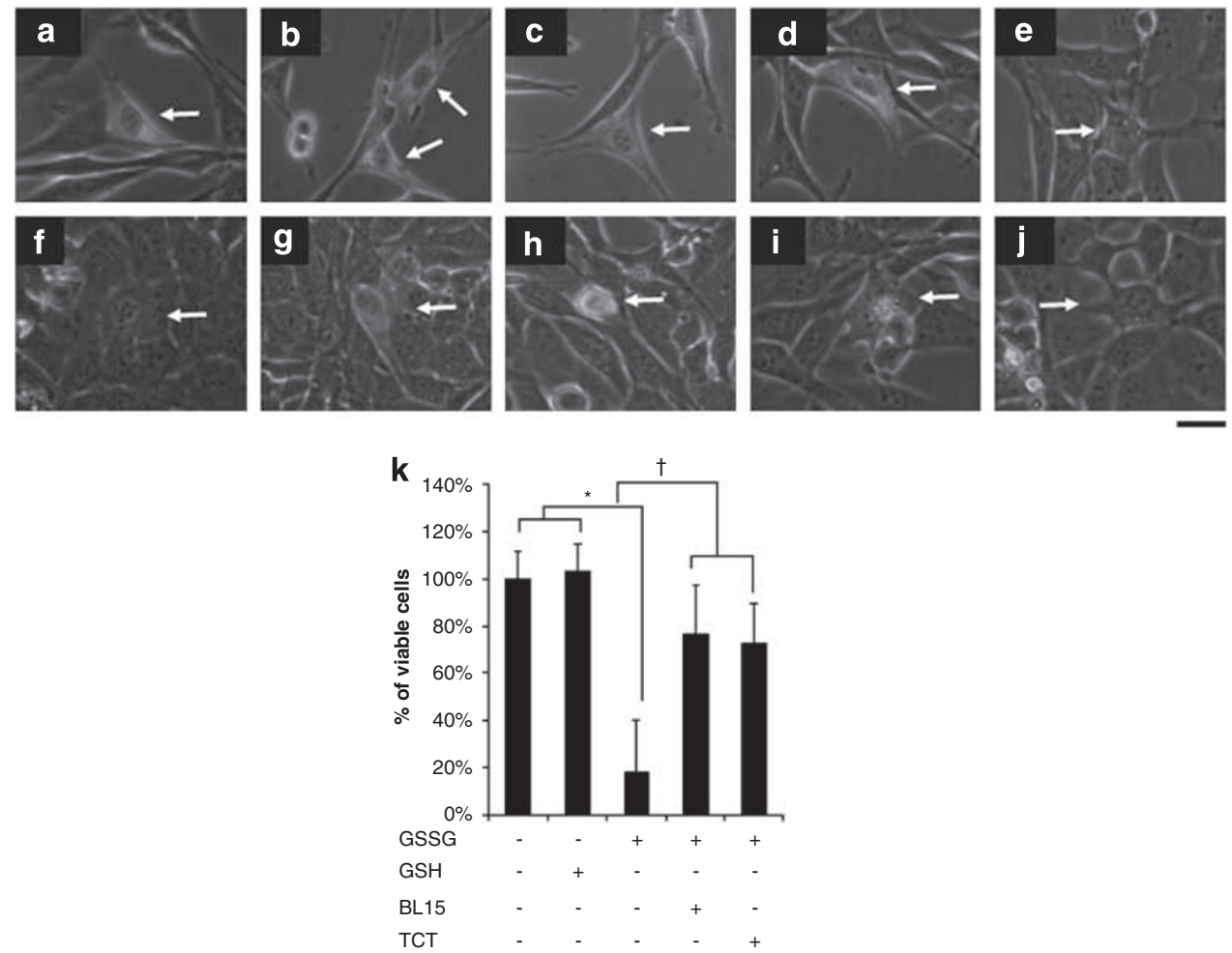

Figure 4 GSSG-induced cell death was attenuated by 12-lipoxygenase inhibitors. Cultured HT4 cells were injected with PBS (a), 500 attomole GSH (b), or 500 attomole GSSG (c-e); $2.5 \mu \mathrm{M} \mathrm{BL}-15$ (d) and $1 \mu \mathrm{M} \mathrm{TCT}$ (e) were treated to culture medium before cytoplasmic injection with GSSG. After $24 \mathrm{~h}$ incubation, cells injected with PBS (f) and GSH (g) were alive, whereas GSSG-injected cells (h) were dead. Treatment of BL-15 (i) and TCT (j) protected neural cells against GSSG challenge (k). Attomoles injected [micromolar]i, $n=3$, Bar, $20 \mu \mathrm{m}$. *Lower than control. ${ }^{*}$ Higher than cells injected with GSSG. Results are mean \pm S.D. ${ }^{*} P<0.05$

rescued HT4 neural cells against GSSG or arachidonic acidinduced cytotoxicity (Figure 9). These observations collectively support the notion, glutamate induces $S$-glutathionylation of 12-lipoxygenase in HT4 neural cells. GRx1 protected against glutamate-induced 12-lipoxygenase glutathionylation as well as cell death.

The estimated concentration of $\mathrm{GSH}$ in the brain is $1.9 \pm 0.37 \mathrm{mM}^{15}$ Consistent with the literature, ${ }^{16}$ resting GSH levels in the mouse brain tissue was noted to be $2.8 \mu \mathrm{mol}$ per gram wet weight (not shown). Acute ischemic stroke, as illustrated in Figure 10a and b, resulted in over sevenfold increase in GSSG levels of the affected brain (Figure 10c). We have previously reported that 12-lipoxygenase-deficient mice are protected against brain injury caused by acute ischemic stroke. ${ }^{5}$ To test whether GSSG is indeed capable of causing brain lesion in vivo, GSSG was directly stereotaxically injected into the cortex. Evidence of clear infarction was noted (Figure 10d). 12-Lipoxygenasedeficient mice were significantly protected against GSSGinduced lesion of the cortex in vivo (Figure 10e and f). These results indicate that under specific conditions GSSG may cause brain lesion in vivo via a 12-lipoxygenase-dependent pathway.

\section{Discussion}

In mammals, the intracellular synthesis of glutathione and its utilization is described by the $\gamma$-glutamyl cycle, a concept that was put forth almost four decades ago. ${ }^{17}$ Reduced glutathione represents the centerpiece of the $\gamma$-glutamyl cycle, involved in several fundamental biological functions, including free radical scavenging, detoxification of xenobiotics and carcinogens, redox reactions, biosynthesis of DNA, proteins and leukotrienes, as well as neurotransmission. Although GSH may form numerous adducts in the human body (see Supplement 2), the most abundant GSH derivative is represented by GSSG. Oxidation of intracellular GSH by oxidants such as hydrogen peroxide and organic peroxides generally leads to the formation of GSSG. GSH can be further oxidized to the sulfenic, sulfinic, and sulfonic acid derivatives via successive two-electron oxidations of the thiol group.

GSSG is mostly viewed as a byproduct of GSH generated following reaction of $\mathrm{GSH}$ with an oxidizing species. As a result, GSSG/GSH ratio in the tissue emerged as a frequently used biochemical measure of oxidative stress (see Supplement 2). Advances in the concept of redox signaling, and redefining of oxidative stress in that light (see Supplement 2), has led to rethinking of the significance of GSSG in the cell (see Supplement 2). It is now widely acknowledged that changes in the cellular reduced/oxidized glutathione ratio trigger signal transduction mechanisms influencing cell survival. GSSG is capable of causing protein S-glutathionylation or reversible formation of protein-mixed disulfides (protein-SSG). Posttranslational reversible S-glutathionylation is known to regulate signal transduction as well as activities of several redox-sensitive thiol proteins. ${ }^{14}$ 

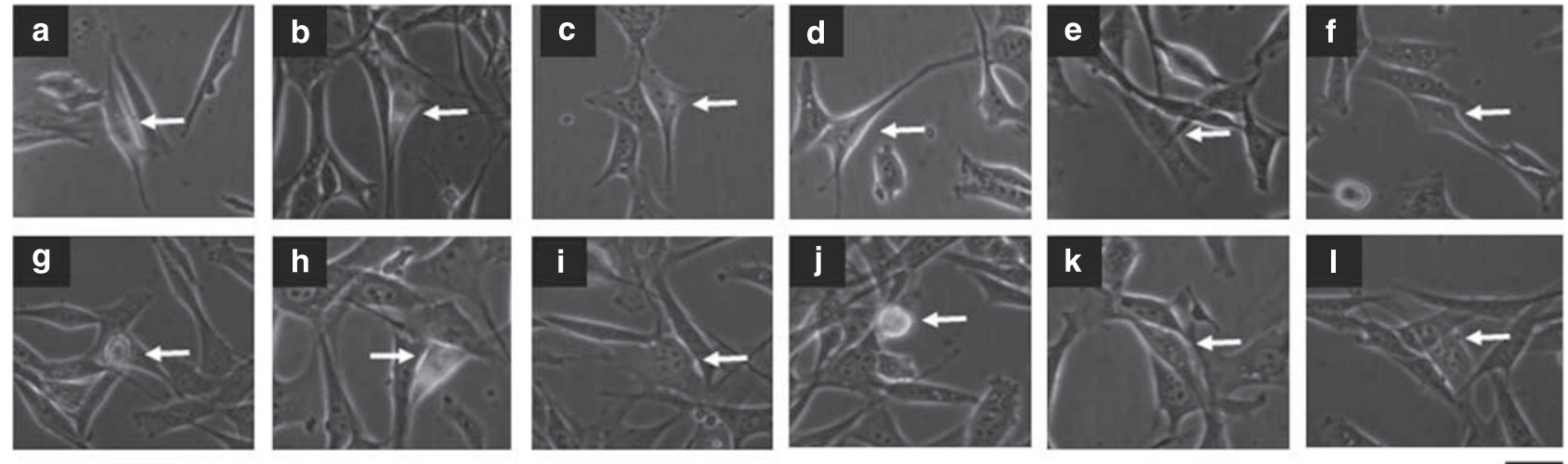

m

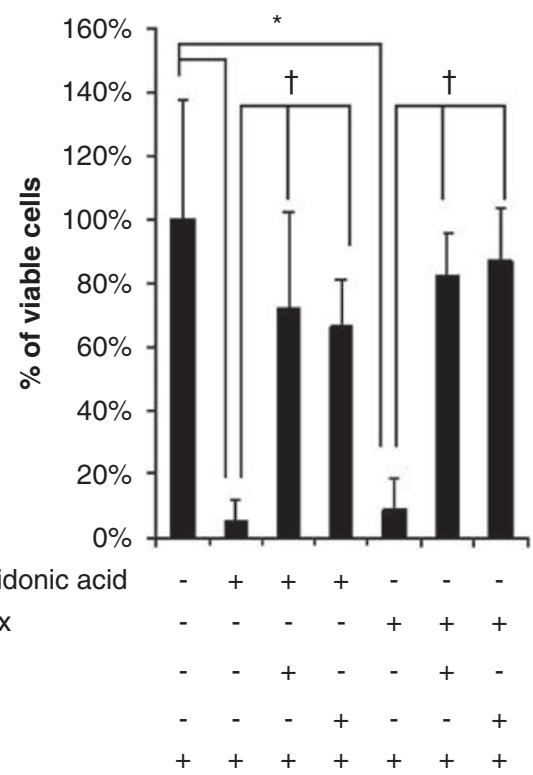

Figure 5 Arachidonic acid or 12-lipoxygenase-induced cell death was attenuated by 12-lipoxygenase inhibitors. Cultured HT4 cells were treated with $50 \mu \mathrm{M} \mathrm{BSO}$ for $12 \mathrm{~h}$ $(\mathbf{a}-\mathbf{l})$, and either 0.15 attomole arachidonic acid (a-c) or $5 \times 10^{-8}$ units 12-Lox (d-f) were injected (marked by arrow) into cytoplasm (a and $\mathbf{d}$, without treatment; $\mathbf{b}$ and $\mathbf{e}$, $2.5 \mu \mathrm{M}$ BL-15 added to culture medium before microinjection; $\mathbf{c}$ and $\mathbf{f}, 1 \mu \mathrm{M} \mathrm{TCT}$ added to culture medium before microinjection). After $24 \mathrm{~h}$ incubation, cells injected with arachidonic acid (g) lost cell viability, whereas BL-15- (h) or TCT-treated (i) cells were protected, and cells injected with 12-Lox (j) lost cell viability, whereas BL-15- (k) and TCT-treated (I) cells were protected (m). Attomoles injected [micromolar], $n=3$, Bar, $20 \mu \mathrm{m}$. ${ }^{*}$ Lower than control, ${ }^{\dagger}$ Higher than cells without treatment of 12 Lox inhibitors. Results are mean \pm S.D. ${ }^{*} P<0.05$

Studies with exogenous nonpermeable GSSG have demonstrated that extracellular GSSG may trigger apoptosis by a redox-mediated p38 mitogen-activated protein kinase pathway (see Supplement 2). Although this addresses the significance of extracellular GSSG, the specific properties of intracellular GSSG remain under veil. GSH is oxidized to GSSG within the cell and pumped to the extracellular compartment. ${ }^{3,4}$ Intracellular compartment being the primary site of GSSG generation, the significance of this disulfide within the cell becomes an important issue to address. Studies examining the significance of intracellular GSSG are complicated by the lack of a specific approach that would only elevate intracellular GSSG levels. For example, exposure of cells to pathogen-related chemicals or to direct oxidant insult does elevate cellular GSSG but activates numerous other aspects of cell signaling (see Supplement 2). Although the study of GSSG-driven reactions in a cell-free system is relatively straightforward in approach, the in vivo significance of such findings remains questionable (see Supplement 2). This work presents first evidence from the use of a microinjection approach to study the significance of GSSG within the cell. Previously, we have utilized this approach to differentially study the cytosolic and nuclear compartments of HT4 cells as well as of primary cortical neurons. ${ }^{5}$ The approach is powerful in instantly and selectively introducing agents into specific compartments of the cell. Results of this study provide the first evidence demonstrating that the specific elevation of GSSG within the cell may cause cell death. Our observation demonstrating loss of mitochondrial membrane potential without affecting cell membrane integrity argues in favor of an apoptotic fate. Disorders of the central nervous system are frequently associated with concomitant glutathione depletion and oxidation (see Supplement 2). Our observation that cells with compromised GSH levels are substantially more sensitive to GSSG-induced death leads to the notion that GSSG may play a role in cell death under 

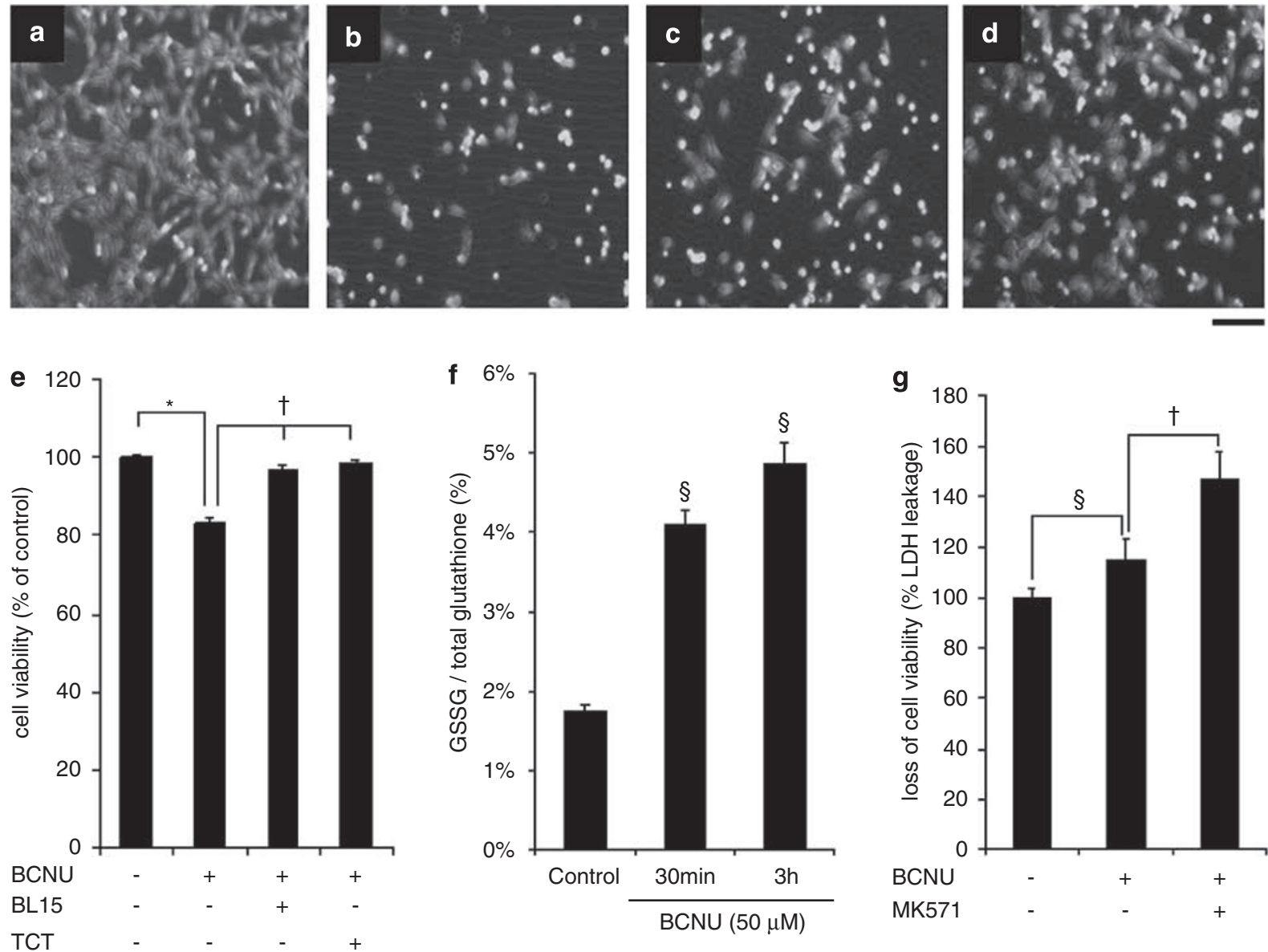

Figure 6 Bischloroethylnitrosourea-induced cell death was attenuated by 12-lipoxygenase inhibitors. HT4 cells were treated with ethanol (a), 50 $\mu \mathrm{M} \mathrm{1,3-Bis}$ (2-chloroethyl)-1-nitrosourea; BCNU (b), $50 \mu \mathrm{M} \mathrm{BCNU}$ and $2.5 \mu \mathrm{M} \mathrm{BL}-15$ (c), or $50 \mu \mathrm{M} \mathrm{BCNU}$ and $1 \mu \mathrm{M} \mathrm{TCT}$ (d). After $12 \mathrm{~h}$ of BCNU treatment, live cells were visualized using calcein-AM (a-d); cell viability was also assayed using a calcein AM-based cell viability kit (e). Cells treated with BL-15 or TCT were more resistant to BCNU-induced loss of cell viability. BCNU treatment increased cellular GSSG over time (f). (g) MK571 $(20 \mu \mathrm{M})$ was added to HT4 cell culture medium for $6 \mathrm{~h}$ before $50 \mu \mathrm{M} \mathrm{BCNU}$ treatment. After $12 \mathrm{~h}$ of adding BCNU into cell culture medium, loss of cell viability was assessed by measuring leakage of lactate dehydrogenase (LDH). MK571 treated HT4 cells were more vulnerable to BCNU-induced loss of cell viability. $n=3$, Bar, $100 \mu \mathrm{m}$. *Lower than control, ${ }^{\dagger}$ Higher than BCNU-challenged HT4 cells, ${ }^{\S}$ Higher than control. Results are mean \pm S.D. ${ }^{*} P<0.05$

conditions of disease and aging. We note that in GSH-sufficient cells (experimental) $0.5 \mathrm{mM}$ GSSG is lethal. In GSH-deficient cells, a condition that mimics oxidative stress situation, the threshold of lethality sharply goes down by 20 -fold to $0.025 \mathrm{mM}$ GSSG. Our estimates show that in HT4 neural cells, total GSH content is in the range of $13 \mathrm{mM}$ (not shown). This is consistent with the literature reporting that under basal conditions, cellular GSH levels is in the tune of $10 \mathrm{mM}$ (see Supplement 2). ${ }^{18}$ In response to oxidant insult, GSSG levels sharply go up and may represent up to $50 \%$ of the total GSH in the cell. ${ }^{13,19}$ Oxidative stress depletes cellular reducing equivalents such $\mathrm{NADPH}^{20}$ compromising GSSG reductase function.

Glutamate toxicity is a major contributor to pathological cell death within the nervous system and is known to be mediated by reactive oxygen species and GSH loss (see Supplement 2). Glutamate-induced death of neural cells is known to be associated with GSH loss and oxidation., ${ }^{6,7}$ Our previous studies have identified 12-lipoxygenase as a key mediator of glutamate-induced neural cell death. ${ }^{9}$ We and others have reported that 12-lipoxygenase-deficient mice are protected against stroke-dependent injury to the brain. ${ }^{9,21} \mathrm{GSH}$ depletion causes neural degeneration by activating the 12-Lox pathway. ${ }^{22,23}$ Observations in this study suggest a direct influence of GSSG on 12-lipoxygenase activation. Arachidonic acid is converted into several more polar products in addition to 12-I-hydroperoxyeicosa-5,8,10,14-tetraenoic acid (12-HPETE) and 12-I-hydroxyeicosa-5,8,10,14-tetraenoic acid (12-HETE) by 12-lipoxygenase. Previously it has been demonstrated that the presence of $0.5-1.5 \mathrm{mM} \mathrm{GSH}$ in the reaction mixture prevents the formation of the more polar products and produces 12-HETE as the only metabolite from arachidonic acid by the 12-lipoxygenase pathway. It was therefore concluded that 12-HPETE peroxidase in the 12-lipoxygenase pathway is a GSH-dependent peroxidase and the more polar products might be formed from the nonenzymatic breakdown of the primary 12-lipoxygenase product of 12-HPETE, owing to insufficient capability of the subsequent peroxidase system to completely reduce 12-HPETE to 12-HETE (see Supplement 2). In a cell system, 
a
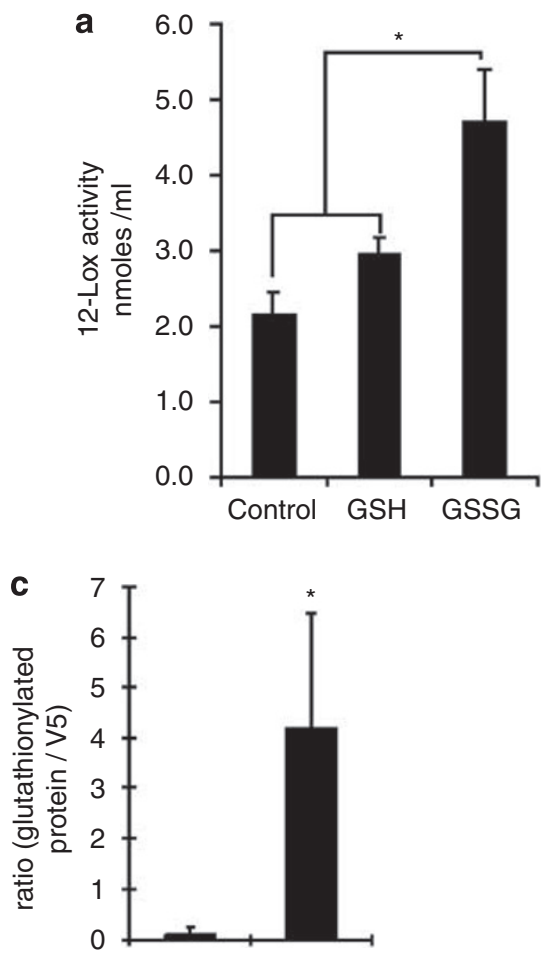

(kD)

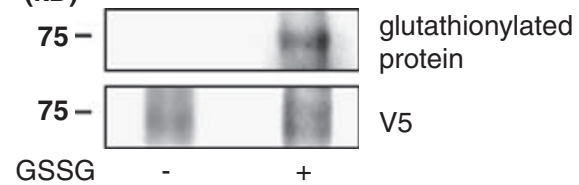

b

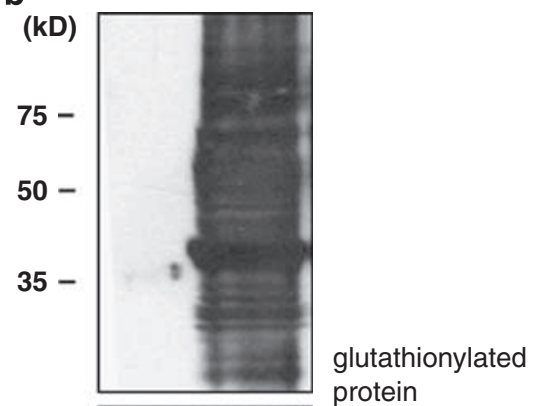

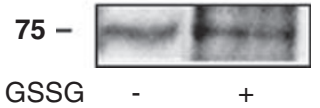
12-Lox

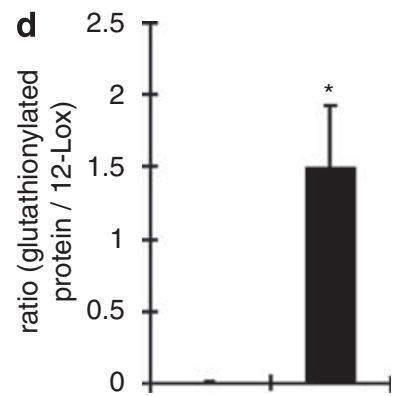

(kD)

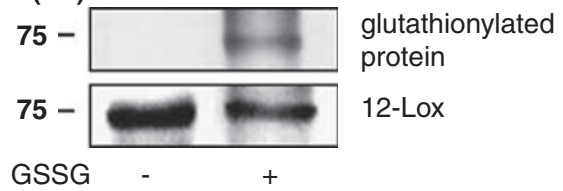

Figure 7 12-Lipoxygenase activity and GSS-12-lipoxygenase formation in response to GSSG. (a) The in vitro activity of 12-Lox was assayed by using a standard spectrophotometric method. The final assay mixture contained $10 \mu \mathrm{mol} / /$ of arachidonic acid and 2 units of 12-Lox. To determine the effects of GSSG, $10 \mu \mathrm{M}$ GSSG or GSH were incubated with this mixture as shown. The absorbance of the reaction mixture was measured at $234 \mathrm{~nm}$ as an index of formation of conjugated dienes. GSSG increased 12-Lox activity by increasing conjugated diene (reaction product) formation. (b) HT4 cell lysates ( $20 \mu \mathrm{g}$ ) were incubated with GSSG (10 mM) for $1 \mathrm{~h}$ and subjected to SDSPAGE and immunoblotting for the detection of formation of protein-glutathione-mixed disulfides (glutathionylation). Cells incubated with GSSG were rich in glutathionylated proteins. (c) After transfection with 12-Lox containing V5 epitope, HT4 cell lysates were incubated with $10 \mathrm{mM}$ GSSG for $1 \mathrm{~h}$ and cell lysates (500 $\mu \mathrm{g}$ ) were subjected to immunoprecipitation (IP) with V5 antibody. IP were subjected to SDS-PAGE and immunoblotting for the detection of formation of protein-glutathione-mixed disulfides. Cell lysates incubated with GSSG increased the formation of GSS-12-Lox. (d) Porcine leukocytes 12-Lox ( $30 \mu \mathrm{g}$ ) was incubated with $10 \mathrm{mM} \mathrm{GSSG}$ for $1 \mathrm{~h}$. Western blot was used for detection of GSS-12-Lox formation. 12-Lox incubated with GSSG increased formation of glutathionylation. $n=3$, Results are mean \pm S.D. ${ }^{*} P<0.05$

disulfides are known to be able to act as biological oxidants that oxidize the zinc-thiolate clusters in metallothionein with concomitant zinc release (see Supplement 2). Intracellular zinc release is known to cause 12-lipoxygenase activation and neurotoxicity. ${ }^{24}$ Studies with BSO-treated GSH-deficient cells highlighted the significance of microinjected free arachidonic acid in neurotoxicity. These observations are consistent with the literature reporting a central role of the free arachidonic acid mobilizing enzyme phospholipase A2 in neurotoxicity (see Supplement 2).

$S$-Glutathionylated proteins (PSSG) can result from thiol/ disulfide exchange between protein thiols (PSH) and GSSG. ${ }^{2}$ Protein S-glutathionylation, the reversible binding of glutathione to low-pKa cysteinyl residues in PSH, is involved in the redox regulation of protein function. Several enzymes are known to undergo this posttranslational modification. Importantly, whether glutathionylation inhibits or augments protein function may vary depending on the individual case. For example, glutathionylation inhibits phosphofructokinase (see Supplement 2), NF- $k$ B (see Supplement 2), glyceraldehydes-3-phosphate dehydrogenase (see Supplement 2), protein kinase $\mathrm{C}-\alpha$ (see Supplement 2), creatine kinase (see Supplement 2), as well as actin (see Supplement 2). In contrast, glutathionylation-dependent gain of protein function has been reported for microsomal glutathione $S$-transferase (see Supplement 2), HIV-1 protease-Cys67 (see Supplement 2), and matrix metalloproteinases (see Supplement 2). Furthermore, specific electron transport proteins of the mitochondria are sensitive to $S$-glutathionylation (see Supplement 2). Consistently, we noted that GSSG-induced cell death was associated with loss of mitochondrial membrane potential. The presence of multiple cysteine residues in 12-lipoxygenase makes it susceptible to $S$-glutathionylation. Results of this study provide first evidence demonstrating that 12-lipoxygenase may be glutathionylated in glutamate challenged neural cells. The finding that both glutaredoxin-1 
a

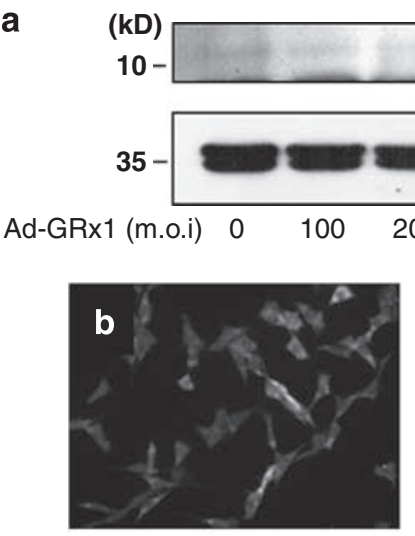

LacZ

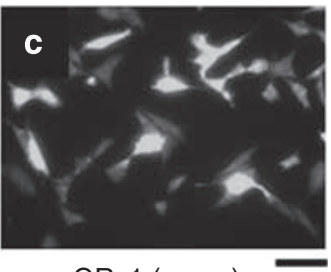

GRx1 (green) e
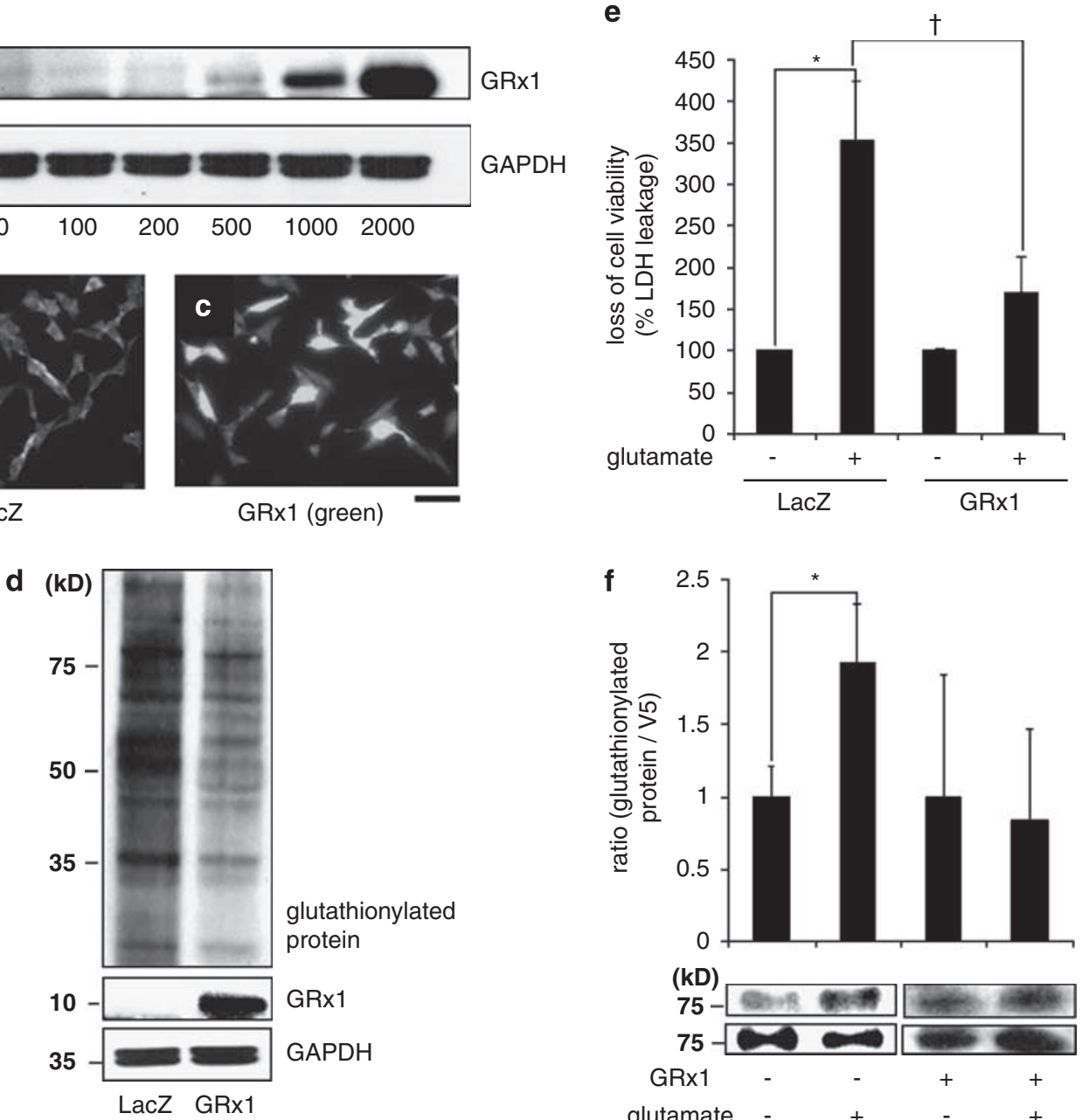

Figure 8 Glutaredoxin-1 reversed glutathionylation in HT4 neural cells and protected cells against glutamate challenge. After $24 \mathrm{~h}$ of seeding, HT4 cells were transfected with adenoviral vector containing the glutaredoxin-1 (ad-GRx1) cDNA construct with dose-dependent manner. (a) Western blot. (b and c) Immunocytochemistry, blue-DAPIstained nuclei; green-GRx1 protein; (b) cells transfected with 2000 m.o.i ad-LacZ; (c) cells tranfected with 2000 m.o.i ad-GRx1). (d) After transfection with ad-LacZ or ad-GRx1 (2000 m.o.i), HT4 cell lysates ( $30 \mu \mathrm{g}$ ) were subjected to SDS-PAGE and immunoblotting for the detection of formation of glutathionylation. HT4 cells transfected with ad-GRx1 expressed lower formation of glutathionylation; (e) HT4 cells were transfected ad-LacZ or ad-GRx1. After $72 \mathrm{~h}$ of transfection, cells were resplit and incubated for $24 \mathrm{~h}$. Cells were challenged with or without $10 \mathrm{mM}$ glutamate for $24 \mathrm{~h}$, and viability of HT4 cells were assessed by measuring leakage of lactate dehydrogenase (LDH). Cells overexpressing GRx1 were more resistant to glutamate-induced loss of cell viability. (f) After transfection with 12-Lox containing V5 epitope, HT4 cells were challenged with $10 \mathrm{mM}$ glutamate for $8 \mathrm{~h}$. Cell lysates $(500 \mu \mathrm{g})$ were subjected to IP with V5 antibody. IP were subjected to SDS-PAGE and immunoblotting for the detection of formation of glutathionylation. Cells treated with glutamate expressed higher formation of GSS-12-Lox. However, in GRx1-transfected cells glutamate-induced 12-Lox glutathionylation was

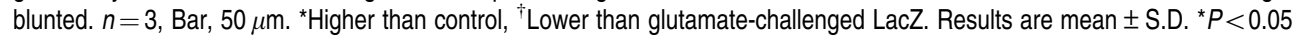

expression as well as delivery may protect cells against glutamate-induced neurotoxicity suggests that glutamateinduced glutathionylation is implicated in the cell death pathway. GSSG is a functionally active byproduct of GSH metabolism that, under appropriate conditions, may trigger cell death. S-glutathionylation seems to be a mechanism that favors 12-lipoxygenase but not the classical caspase-3dependent (see Supplement 2) death pathway.

The GSSG reductase inhibitor BCNU, clinically known as carmustine, is a proven chemotherapeutic agent (see Supplement 2). Cytotoxicity is a widely recognized side effect of BCNU (see Supplement 2). As BCNU treatment is associated with GSSG accumulation in cells (see Supplement 2), the significance of GSSG in BCNU-induced cytotoxicity is of interest. Observations of this study support that both
GSSG as well as BCNU-induced cell death follow the same 12-lipoxygenase-dependent path suggesting the possibility that BCNU may cause cell death via GSSG. Affirmation of this hypothesis would warrant examining the significance of pro-GSSG strategies for cancer therapy. Major forms of cancer therapy including radiation therapy as well as chemotherapy rely on oxygen-centered free radicals for their action. Thus, these interventions cause overt oxidative insult associated with elevated levels of cellular and tissue GSSG (see Supplement 2). GSSG generated within the cell is pumped out of the cell perhaps to avert cytotoxicity caused by GSSG accumulation. Approaches to selectively block the GSSG efflux mechanisms in cancer cells might be useful for cancer therapy. Findings of this study support that BSO sensitizes cells to GSSG-induced death. Indeed, BSO has 

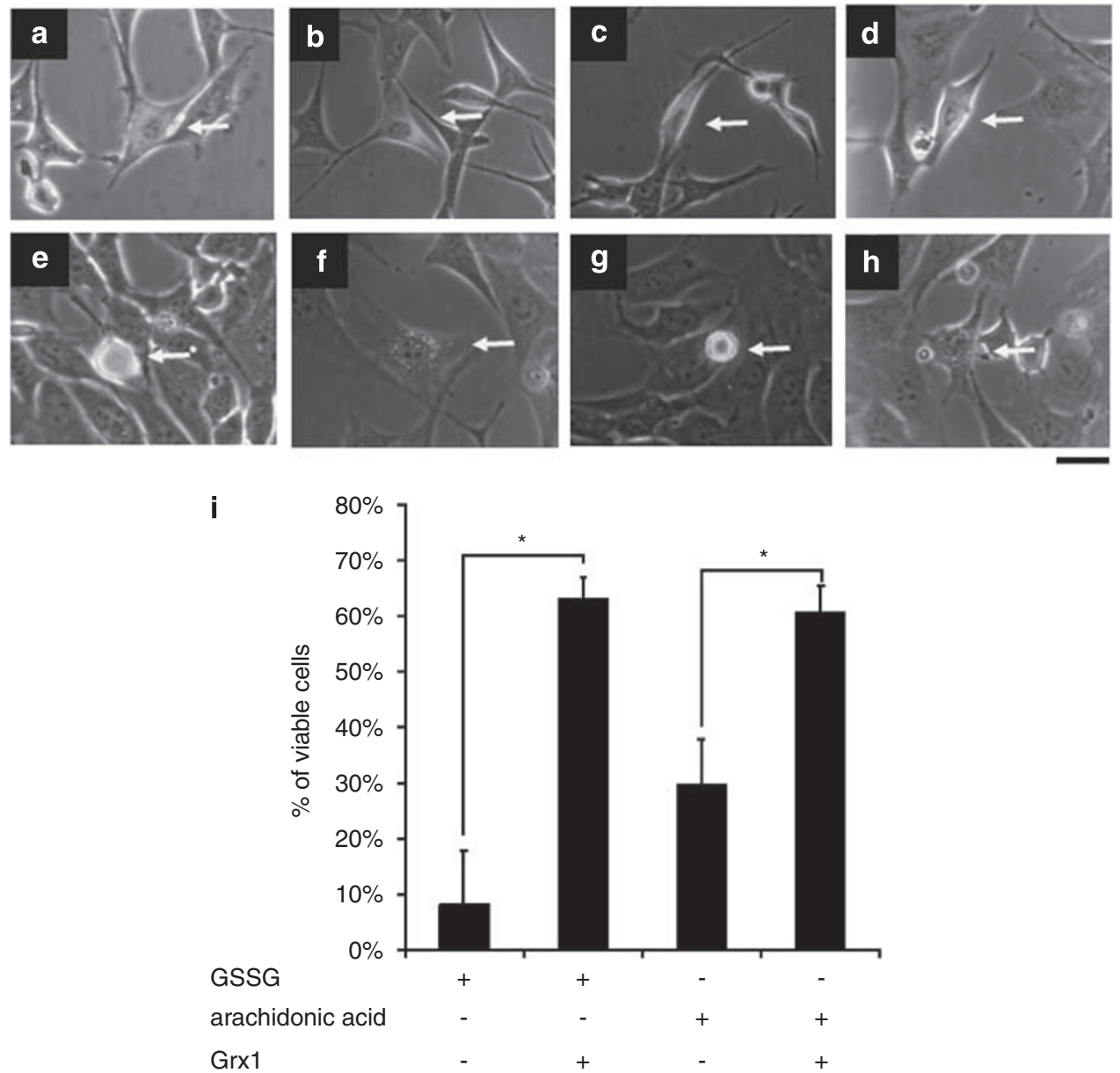

Figure 9 Glutaredoxin-1 microinjection protected HT4 neural cells against GSSG as well as arachidonic acid challenge. Cultured HT4 cells were either injected 500 attomole GSSG ( $\mathbf{a}$ and $\mathbf{b}$ ) or 0.15 attomole arachidonic acid (c and $\mathbf{d})$, and coinjected with 2 attomole glutaredoxin-1 (b and $\mathbf{d})$. After $24 \mathrm{~h}$ incubation, cells injected with GSSG (e) lost cell viability, whereas glutaredoxin-1 coinjected cells (f) were significantly protected. Cells injected with arachidonic acid (g) lost cell viability, whereas glutaredoxin-1 coinjected cells (h) were protected (i). Attomoles injected [micromolar]i, $n=3$, Bar, $20 \mu \mathrm{m}$. Results are mean \pm S.D. ${ }^{*} P<0.05$

been founds to be a useful adjunct for both radiation (see Supplement 2) as well as chemotherapy (see Supplement 2). Also, inhibition of GSSG efflux by inhibition of MRP1 enhanced BCNU-induced cytotoxicity suggesting that GSSG extrusion plays a role in neural sensitivity to GSSG.

Three-fourth of all stroke in humans occur in distributions of the middle cerebral artery (see Supplement 2). Therefore, MCAO represents a common approach to study stroke in small as well as large animals. ${ }^{5}$ Using a MCAO approach we were able to obtain just over $16 \%$ infarction of the ipsilateral hemisphere as assessed by MRI. Stroke caused eightfold increased in GSSG levels in the affected brain tissue. This is consistent with the known incidence of oxidative stress in the stroke-affected brain. ${ }^{25}$ Our observation that the stereotaxic injection of GSSG to the brain may cause lesion by a 12-lipoxygenase-sensitive mechanism leads to question the significance of GSSG in numerous brain pathologies commonly associated with elevated levels of GSSG in the brain. ${ }^{26,27}$

Taken together, this work presents first evidence demonstrating that intracellular GSSG may trigger cell death. GSSG cytotoxicity is substantially enhanced under conditions of compromised cellular GSH levels as observed during a wide variety of disease conditions as well as aging (see Supplement 2). BSO-assisted glutathione-lowering approaches are known to be effective to facilitate both chemotherapy as well as radiation therapy. Furthermore, BCNU-dependent arrest of GSSG reductase activity leads to the elevation of cellular GSSG and has chemotherapeutic functions. Findings of this study lead to question the significance of GSSG in such processes. From the standpoint of novel therapeutic approaches, strategies directed at improving or arresting cellular GSSG clearance may be effective in minimizing oxidative stress-related tissue injury or potentiating the killing of tumor cells, respectively.

\section{Materials and Methods}

Materials. The following materials were obtained from the sources indicated. Ascorbic acid, arachidonic acid, L-glutamic acid monosodium salt, dimethyl sulfoxide, oxidized L-glutathione, reduced L-glutathione, 1,3-bis(2-chloroethyl)-1nitrosourea (BCNU), L-buthionine-[S,R]-sulfoximine (Sigma Chemical Co. St. Louis, MO, USA); $\alpha$-tocotrienol ( $90 \%$; Carotech Inc.); 12-lipoxygenase from porcine leukocytes, MK-571, 5,6,7-trihydroxyflavone (BL-15; baicalein; Biomol Research Laboratories); tetramethylrhodamine methyl ester (TMRM), Qdot 605 ITK 

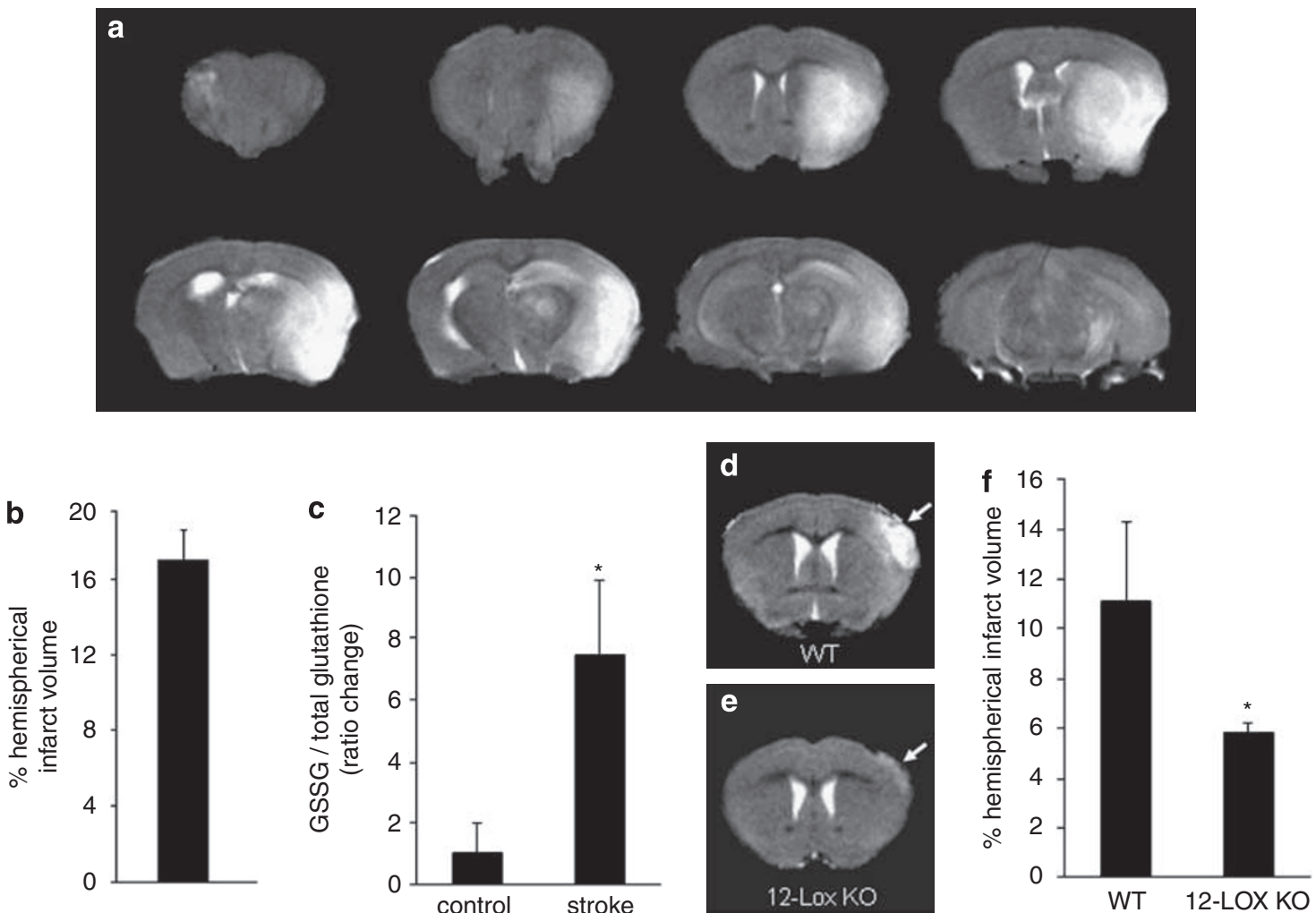

Figure 10 12-Lipoxygenase-deficient mice were resistant to GSSG-induced brain damage. Transient focal cerebral ischemia was induced in 8- to 10-week-old C57BL6/J mice $(n=3)$ by middle cerebral artery occlusion for $90 \mathrm{~min}$. (a) Brain infarction was detected by T2-weighted MRI images at $24 \mathrm{~h}$ after reperfusion. (b) MRI images were used to determine infarct size as a percentage of the hemispherical infract volume. (c) HPLC coulometric electrode array detector was used to detect GSSG and GSH level in the infarcted tissue, and stroke-induced injured hemisphere contained elevated level of GSSG. GSSG was injected to the brain cortex of C57BL6/J (control, $n=3$ ) or 12-Lox knockout (12-Lox ${ }^{-1}, n=3$ ) mice. Two days after injection, T2-weighted MRI images were collected. WT mice injected with GSSG (d) had clear lesion in the brain whereas 12-Lox-deficient mice (e) were significantly resistant to GSSG-induced brain injury (f). Solid arrows represent damage caused by GSSG. Results are mean \pm S.D. ${ }^{*} P<0.05$

streptavidin conjugate kit $2 \mu \mathrm{M}$ solution, dextran alexa fluor 488, anti-V5 antibody, calcein acetoxymethyl ester, PLUS Reagent, lipofectamine LTX Reagent (Invitrogen Corporation, Carlsbad, CA, USA); 12-lipoxygenase (murine leukocyte) polyclonal antiserum (Cayman Chemical); anti-glutathione monoclonal antibody (ViroGen Corporation); V5 antibody affinity purified agarose immobilized conjugate (Bethyl Laboratories); goat anti-mouse glutaredoxin-1/GLRX1 antibody (R\&D Systems Inc.); glutaredoxin-1, glutaredoxin-1 antibody (Abcam); membrane potential assay kit (Molecular Devices Corp.).

For cell culture, Dulbecco's modified Eagle's medium, fetal calf serum, and penicillin and streptomycin were purchased from Invitrogen. Culture dishes were obtained from Nunc, Denmark.

Cell culture. Mouse hippocampal HT4 neural cells were grown in Dulbecco's modified Eagle's medium supplemented with $10 \%$ fetal calf serum, $100 \mathrm{U} / \mathrm{ml}$ penicillin, and $100 \mu \mathrm{g} / \mathrm{ml}$ streptomycin at $37^{\circ} \mathrm{C}$ in humidified atmosphere of $95 \%$ air and $5 \% \mathrm{CO}_{2}$ as described previously. ${ }^{5-7,9,28}$ Glutamate treatment: Immediately before experiments, the culture medium was replaced with fresh medium supplemented with serum and antibiotics. Glutamate $(10 \mathrm{mM})$ was added to the medium as an aqueous solution. No change in the medium $\mathrm{pH}$ was observed in response to the addition of glutamate ${ }^{6,9}$ L-Buthionine-sulfoximine(BSO) treatment: Before experiments, the culture medium was replaced as described above, and freshly prepared BSO $(50 \mu \mathrm{M})$ in sterile PBS was added to the medium as described in relevant legends. 1,3-Bis(2-chloroethyl)-1-nitrosourea(BCNU) treatment: Before experiment, the culture medium was replaced as described above, and BCNU $(50 \mu \mathrm{M})$ prepared in ethanol was added to the medium. Respective controls were treated with an equal volume of ethanol. $\alpha$-Tocotrienol (TCT) and 5,6,7, -trihydroxyflavone (BL-15) treatment: A stock solution of TCT was prepared in ethanol, and BL-15 was prepared in dimethyl sulfoxide (DMSO). Before experiments, culture medium was replaced with fresh medium supplemented with serum and antibiotics, and TCT $(1 \mu \mathrm{M})$ or BL-15 $(2.5 \mu \mathrm{M})$ was added to the culture dishes as described in relevant legends.

Microinjection. The mouse hippocampal HT4 cells $\left(0.1 \times 10^{6} /\right.$ plate $)$ were grown on $35 \mathrm{~mm}$ plates $24 \mathrm{~h}$ before microinjection. As previously described, ${ }^{5,28}$ microinjection was performed using a micromanipulator Femtojet B 5247 and Injectman NI 2 (Eppendorf, Hamburg, Germany) with $80 \mathrm{hPa}$ of pressure and $0.2 \mathrm{~s}$ duration. The compensation pressure during injection was $40 \mathrm{hPa}$. The glass micropipettes were made from GD-1 glass capillaries (Narishige, Japan) by using a Narishige PC-10 Puller with heater set at $52.7^{\circ} \mathrm{C}$. Cells were injected with GSSG, GSH, sham (PBS) or reagents described in the relevant legends, and live and dead cells were counted at $24 \mathrm{~h}$ after microinjection. Stock solutions of GSSG and GSH were freshly prepared in sterile PBS, and coinjected with QDot streptavidin conjugate with the emission maximum near $605 \mathrm{~nm}$ (Invitrogen). QDot streptavidin conjugate was used as a fluorescent marker to localize the injection site. Digital images were collected using a specialized phase contrast as well as a fluorescent Zeiss Axiovert 200M microscope suited for imaging cells grown in routine culture plates. The sample stage was maintained at $37^{\circ} \mathrm{C}$, and the sample gas environment was maintained exactly as in the culture incubator.

Reduced (GSH) and oxidized (GSSG) glutathione assay. GSH and GSSG were detected simultaneously in HT4 cells and mice brain tissues using an HPLC coulometric electrode array detector (CoulArray Detector, model 5600 with 12 channels; ESA Inc., Chelmsford, MA, USA) as described in our laboratory previously., ${ }^{5,9,29}$ The CoulArray detector employs multiple channels set at specific redox potentials. Data were collected using channels set at 600,700 , and $800 \mathrm{mV}$. The samples were snap frozen and stored in liquid nitrogen until HPLC assay. Sample preparation, composition of the mobile phase, and specification of the column used were as previously reported. ${ }^{6,29}$ 
Measurement of mitochondrial membrane potential $(\Delta \psi)$. Mitochondrial membrane $\Delta \psi$ was measured using the fluorescent lipophilic cationic dye TMRM, which accumulates within mitochondria in a potential dependent manner. ${ }^{30}$ Following $24 \mathrm{~h}$ of seeding, HT4 cells were injected with 500 attomole GSSG or sham (PBS). Dextran alexa fluor 488 was coinjected, and used as a fluorescent marker. After $2 \mathrm{~h}$ incubation, cells were resuspended in Hanks' balanced salt solution and stained with $8 \mathrm{nM}$ TMRM and $0.5 \mu \mathrm{l} / \mathrm{ml}$ plasma membrane potential indicator (PMPI) for $30 \mathrm{~min}$ at $37^{\circ} \mathrm{C}$ in the dark. The cells were washed with PBS, and digital images of stained live cells were collected using a Zeiss Axiovert 200M microscope. ${ }^{8,31,32}$

Cell viability. The viability of cells in culture was assessed by measuring leakage of lactate dehydrogenase (LDH) from cells into media $24 \mathrm{~h}$ following glutamate treatment using an in vitro toxicology assay kit from Sigma Chemical Co. The protocol has been described in detail in a previous report. ${ }^{33}$ In brief, LDH leakage was determined using the following equation: \% total LDH leaked $=(\mathrm{LDH}$ activity in the cell culture medium/total LDH activity) $\times 1000^{5,9,28}$ Total LDH activity represents the sum of LDH activities in the cell monolayer, detached cells, and the cell culture medium. Survival of HT4 cells was also quantified by using a calcein acetoxymethyl ester (AM) assay. ${ }^{34,35}$ Briefly, HT4 cells (40 000/well) were seeded in 12-well plates. After $2 \mathrm{~h}$ of incubation, cells were treated with either $2.5 \mu \mathrm{M} \mathrm{BL}-15$ or $1 \mu \mathrm{M} \mathrm{TCT}$. After $6 \mathrm{~h}$ incubation, cells were treated with $50 \mu \mathrm{M} \mathrm{BCNU}$. Following $12 \mathrm{~h}$ incubation, media was removed from each well, and $5 \mu \mathrm{M}$ calcein AM in sterile PBS was added. After incubation at $37^{\circ} \mathrm{C}$ for $1 \mathrm{~h}$, fluorescence was measured by using the fluorescence multi-well plate reader Cyto Fluor II (PerSeptive Biosystems) with the excitation wavelength at $485 \mathrm{~nm}$ and the emission wavelength of $530 \mathrm{~nm}$.

Determination of 12-lipoxygenase activity. The in vitro activity of 12Lox was assayed using a standard spectrophotometric method measuring the increase in the formation of conjugated dienes from the substrate arachidonic acid as described, ${ }^{36}$ with minor modifications as specified below. To ensure greater solubility of arachidonic acid and to minimize the use of ethanol in the assay medium, the potassium salt of arachidonic acid was freshly prepared by mixing arachidonic acid with $0.1 \mathrm{M} \mathrm{KOH}(1: 1)$. The final assay mixture (total volume of $1 \mathrm{ml}$ ) contained $10 \mu \mathrm{mol} / \mathrm{l}$ of arachidonic acid $(10 \mu \mathrm{l}$ from $1 \mathrm{mmo} / / \mathrm{lstock})$ and 2 units of 12 Lox (porcine leukocyte enzyme) in $100 \mathrm{mmol} / \mathrm{I}$ Tris- $\mathrm{HCl}$ buffer $(\mathrm{pH}$ 7.4). The mixture was then gently mixed, reaction was started by adding the enzyme, and absorbance of the reaction mixture was measured at $234 \mathrm{~nm}$ (as an index of formation of conjugated dienes) using a Shimadzu model UV-2401PC spectrophotometer. The activity of 12-Lox was calculated from the absorbance values as $n$ mole/min using the $\varepsilon$ of $2.52 \times 10^{4} \mathrm{~mol} / /^{-1}$ and normalized as $\%$ control. $^{5}$

12-Lipoxygenase overexpression. This procedure was performed as described previously. ${ }^{8,9}$ Following $24 \mathrm{~h}$ of seeding $\left(0.5 \times 10^{6} /\right.$ well), HT4 cells were transfected with plasmid pcDNA3.1 + 12-Lox (ResGen; Invitrogen) or empty pcDNA 3.1 containing V5 epitope tag using Lipofectamine LTX Reagent (Invitrogen). Cells were maintained in regular culture conditions for $48 \mathrm{~h}$ to allow for protein expression, and cells or cell lysates were treated as described in the respective figure legends.

Immunoprecipitation and immunoblots. HT4 cells $\left(0.5 \times 10^{6} /\right.$ well) were seeded in six-well plates for immunoprecipitation as previously described. ${ }^{28}$ Cells were transfected with pcDNA3.1 + 12-Lox or empty pcDNA 3.1 containing V5 epitope tag as described above. During harvest, the cells were washed with ice-cold phosphate-buffered saline $(\mathrm{pH} 7.4)$ and lysed with $0.2 \mathrm{ml}$ lysis buffer (Cell Signaling Technology Inc). Protein concentration was determined using the BCA protein assay kit (Pierce Biotechnology). Cells were treated as described in the respective figure legends, and then cell lysates $(500 \mu \mathrm{g})$ were incubated with $20 \mu \mathrm{l}$ immunoprecipitating antibody overnight at $4^{\circ} \mathrm{C}$ (V5 antibody affinity purified agarose immobilized conjugate; Bethyl Laboratories Inc). Immunoprecipitated complexes were washed four times with lysis buffer (centrifugation at $1000 \times g$ at $4^{\circ} \mathrm{C}$ for $5 \mathrm{~min}$ ), and boiled for $30 \mathrm{~min}$ under nonreducing conditions. Next, equal volumes of samples were loaded onto SDS-PAGE gel and probed with anti-V5 antibody (1:5000 dilution; Invitrogen).

GSSG-induced glutathionylation. HT4 cell lysates $(20 \mu \mathrm{g})$ or 12-lipoxygenase from porcine leukocytes $(30 \mu \mathrm{g})$ were incubated with $10 \mathrm{mM}$ GSSG or the same volume of PBS at $37^{\circ} \mathrm{C}$. After $1 \mathrm{~h}$ incubation, samples were either processed for immunoprecipitation or subjected to SDS-PAGE under nonreducing conditions. Samples were quickly centrifuged, resuspended with sample buffer lacking thiol reductant, and boiled for $30 \mathrm{~min}$. After quick centrifugation, samples were loaded to $10 \%$ SDS-PAGE, and transferred to PVDF. After transfer, membranes were blocked using 10\% nonfat milk overnight at $4{ }^{\circ} \mathrm{C}$, and incubated with anti-glutathione monoclonal antibody $(1: 500$ dilution; ViroGen Corporation), or anti-12-lipoxygenase polyclonal antibody ( $1: 1000$ dilution; Cayman Chemical) for $2.5 \mathrm{~h}$. Membranes were washed three times. Next, blots were incubated with secondary antibody $(1: 2000$ dilution; Amersham anti-mouse IgG horseradish peroxidase linked whole antibody; GE Healthcare), or (1:3000 dilution; Amersham anti-rabbit IgG horseradish peroxidase linked whole antibody; GE Healthcare) for $1 \mathrm{~h}$, and visualized by enhanced chemiluminescence western blotting detection reagent (GE Healthcare).

Adenoviral expression of glutaredoxin-1. The mouse hippocampal HT4 cells $\left(0.5 \times 10^{6} /\right.$ well $)$ were grown on six-well plates for $24 \mathrm{~h}$, and infected with specific multiplicities of infection (m.o.i. 100, 200, 500, 1000, and 2000) of adenoviral vector containing the GRx1 CDNA construct (Ad-GRx1, a gift from Dr. JJ Mieyal, Case Western Reserve University, Cleveland, OH, USA) or ad-LacZ (control) in $750 \mu \mathrm{l}$ of serum-free DMEM for $4 \mathrm{~h}$. Cells were cultured for $72 \mathrm{~h}$ in Dulbecco's modified Eagle's medium supplemented with $10 \%$ fetal calf serum, $100 \mathrm{U} / \mathrm{ml}$ penicillin, and $100 \mu \mathrm{g} / \mathrm{ml}$ streptomycin. Transfected cells or cell lysates were treated as described in relevant figure legends. After protein extraction, protein concentrations were determined using BCA protein reagents. Samples ( $30 \mu \mathrm{g} / \mathrm{lane}$ ) were separated on $12 \%$ SDS-PAGE and probed with anti-glutaredoxin-1 1 : 1000 dilution; R\&D Systems Inc.). To evaluate the loading efficiency, membranes were reprobed with anti-GAPDH.

Immunocytochemistry. HT4 cells $\left(0.5 \times 10^{6} /\right.$ well) were seeded in $35 \mathrm{~mm}$ plates for $24 \mathrm{~h}$, and transfected with ad-GRx1 as described above. Cells were washed with PBS three times and then fixed in 10\% buffered formalin for $20 \mathrm{~min}$. Next, the cells were washed three times with PBS followed by permeabilization using $0.1 \%$ Triton X-100/PBS for $15 \mathrm{~min}$. The cells were washed three times with PBS and incubated with $10 \%$ goat serum (Vector Laboratories) for $1 \mathrm{~h}$ at room temperature. Cells were then incubated with glutaredoxin-1 antibody $(1: 100$, in $10 \%$ goat serum) overnight at $4^{\circ} \mathrm{C}$. After incubation with primary antibody, cells were washed with PBS three times and incubated with an Alexa-flour rabbit (green) for $1 \mathrm{~h}$ at room temperature. After three washes with PBS and incubation with $4^{\prime}, 6^{\prime}$-diamino-2-phenylindole $(1: 10000)$ for 2 min, cells were washed with PBS and mounted in gelmount (aqueous mount; Vector Laboratories) for microscopic imaging as described previously. ${ }^{28}$

Stereotaxic injection. 12-Lox knockout (B6.129S2-Alox15 ${ }^{\mathrm{tm} / \text { Fun }}$ ) and corresponding background C57BL6/J mice were obtained from Jackson Laboratory. Young (8-10 weeks of age; $24-27 \mathrm{~g}$ ) male mice were anesthetized with isoflurane in oxygen-enriched air delivered through a facemask. The mouse was secured by ear bars, the skull was exposed, and injected with $5 \mu$ l of GSSG stock (100 mM) in sterile PBS into the cortex using a Hamilton RN syringe with a stainlesssteel needle (Hamilton Company, Reno, NV; USA). The location of injection site (coordinates: $-0.5 \mathrm{~mm}$ anterior, $3.5 \mathrm{~mm}$ lateral, and $1.0 \mathrm{~mm}$ ventral to bregma) was measured by Benchmark Stereotaxic Digital (myNeurolab.com, St. Louis, MO, USA). To minimize pressure-induced damage, GSSG was injected at a rate of $0.2 \mu \mathrm{l} / \mathrm{min}$. All animal protocols were approved by the Institutional Laboratory Animal Care and Use Committee (ILACUC) of the Ohio State University, Columbus, OH, USA.

Mouse stroke model. Transient focal cerebral ischemia was induced in mice described above by middle cerebral artery (MCA) occlusion. Occlusion of the right middle cerebral artery was achieved by using the intraluminal filament insertion technique as previously described. ${ }^{5,37,38}$ Briefly, a 6-0 nylon monofilament was inserted into the internal carotid artery, via the external carotid artery. Then the filament tip was positioned for occlusion at a distance of $6 \mathrm{~mm}$ beyond the internal carotid artery-pterygopalatine artery bifurcation. We observed that this approach results in a $60-70 \%$ drop in cerebral blood flow as measured by laser Doppler (DRT4, Moor Instruments). Once the filament was secured, the incision was sutured and the animal was allowed to recover from anesthesia in its home cage. After $90 \mathrm{~min}$ of occlusion, the animal was briefly reanesthetized, and reperfusion was initiated via withdrawal of the filament. This surgical protocol typically results in a core infarct limited to the parietal cerebral cortex and caudate putamen of the right hemisphere. After $24 \mathrm{~h}$ of reperfusion, a T2-weighted image was taken to measure infarct volume, and left and right hemispheres were collected in liquid nitrogen for GSH and GSSG measurements. 
Magnetic resonance imaging. T2-weighted imaging was performed on stereotaxically injected as well as stroke-affected mice. Imaging experiments were carried out in an $11.7 \mathrm{~T}(500 \mathrm{MHz}) \mathrm{MR}$ system comprised of a vertical bore magnet (Bruker Biospin, Ettlingen, Germany) as described previously by our group. ${ }^{39}$ Highresolution magnetic resonance imaging was performed on mice brain. Mice were anesthetized by inhaled isoflurane via a nose cone. The mouse under MR scan was placed in a MR compatible animal holder with the proper respiratory sensor unit. The mouse was held with tape during contingent supply of a mixture of carboxin (95\% air and $5 \%$ carbon dioxide) and isoflurane through tubing. A $30 \mathrm{~mm}$ birdcage coil was used which surrounds the mouse brain. The animal was then placed inside the radio frequency coil (resonator) and finally the whole arrangement was placed inside the vertical magnet. A spin echo (SE) sequence was used to acquire T2-weighted MR images from the mouse head on the 11.7-T MRI system. A spin echo technique with rapid acquisition with relaxation enhancement (RARE) sequence providing 8 echo train length (ETL) was used with the following parameters: field of view $(F O V)=$ $30 \times 30 \mathrm{~mm}$, acquisition matrix $256 \times 256$, repetition time $(T R)=3000 \mathrm{~ms}$, echo time $(\mathrm{TE})=30 \mathrm{~ms}$, flip angle $(\mathrm{FA})=180$ degrees, images in acquisition $=15$, resolution $=8.533$ pixels $/ \mathrm{mm}$, and number of averages 4 . Shim currents were initialized by manual adjustments on all linear and higher order field inhomogeneities. After several localizer scans were completed, a T2-weighted spin echo RARE sequence was applied to generate 15 images corresponding to 15 short axis slices. Postimage processing was done using ImageJ software $(\mathrm{NIH})$. For strokevolume calculation from $2 \mathrm{D}$ images, raw MRI images were first converted to digital imaging and communications in medicine (DICOM) format and read into ImageJ software. By delineating both the whole brain and injured part of the brain borders, whole brain area and injury area were calculated. The areas were summed from all short axis slices and the volumes were computed from the area of traced boarders by multiplying slice thickness. A percentage fraction of infarction to whole brain was determined from the volumes calculated as above.

Statistical analyses. Data are reported as mean \pm S.D. of at least three experiments. Difference between two means was tested by Student's $t$-test. Comparisons between multiple groups were made by analysis of variance. $P<0.05$ was considered statistically significant.

\section{Acknowledgements. This study was supported by NIH Grant NS42617.}

1. Lenton $\mathrm{KJ}$, Therriault $\mathrm{H}$, Wagner JR. Analysis of glutathione and glutathione disulfide in whole cells and mitochondria by postcolumn derivatization high-performance liquid chromatography with ortho-phthalaldehyde. Anal Biochem 1999; 274: 125-130.

2. Rossi R, Dalle-Donne I, Milzani A, Giustarini D. Oxidized forms of glutathione in peripheral blood as biomarkers of oxidative stress. Clin Chem 2006; 52: 1406-1414.

3. Sen CK, Rahkila P, Hanninen O. Glutathione metabolism in skeletal muscle derived cells of the L6 line. Acta Physiol Scand 1993; 148: 21-26.

4. Srivastava SK, Beutler $E$. The transport of oxidized glutathione from human erythrocytes. J Biol Chem 1969; 244: 9-16.

5. Khanna S, Roy S, Slivka A, Craft TK, Chaki S, Rink C et al. Neuroprotective properties of the natural vitamin E alpha-tocotrienol. Stroke 2005; 36: 2258-2264.

6. Sen CK, Khanna S, Roy S, Packer L. Molecular basis of vitamin E action. Tocotrienol potently inhibits glutamate-induced pp60(c-Src) kinase activation and death of HT4 neuronal cells. J Biol Chem 2000; 275: 13049-13055.

7. Tirosh O, Sen CK, Roy S, Packer L. Cellular and mitochondrial changes in glutamateinduced HT4 neuronal cell death. Neuroscience 2000; 97: 531-541.

8. Khanna S, Roy S, Parinandi NL, Maurer M, Sen CK. Characterization of the poten neuroprotective properties of the natural vitamin E alpha-tocotrienol. J Neurochem 2006 98: $1474-1486$.

9. Khanna S, Roy S, Ryu H, Bahadduri P, Swaan PW, Ratan RR et al. Molecular basis of vitamin $\mathrm{E}$ action: tocotrienol modulates 12-lipoxygenase, a key mediator of glutamateinduced neurodegeneration. J Biol Chem 2003; 278: 43508-43515.

10. Galter D, Mihm S, Droge W. Distinct effects of glutathione disulphide on the nuclea transcription factor kappa B and the activator protein-1. Eur J Biochem 1994; 221: 639-648.

11. Haddad JJ, Safieh-Garabedian B, Saade NE, Lauterbach R. Inhibition of glutathionerelated enzymes augments LPS-mediated cytokine biosynthesis: involvement of an IkappaB/NF-kappaB-sensitive pathway in the alveolar epithelium. Int Immunopharmacol 2002; 2: 1567-1583

12. Hirrlinger J, Konig J, Keppler D, Lindenau J, Schulz JB, Dringen R. The multidrug resistance protein MRP1 mediates the release of glutathione disulfide from rat astrocytes during oxidative stress. J Neurochem 2001; 76: 627-636.
13. Minich T, Riemer J, Schulz JB, Wielinga $P$, Wijnholds J, Dringen R. The multidrug resistance protein 1 (Mrp1), but not Mrp5, mediates export of glutathione and glutathione disulfide from brain astrocytes. J Neurochem 2006; 97: 373-384.

14. Mieyal JJ, Gallogly MM, Qanungo S, Sabens EA, Shelton MD. Molecular mechanisms and clinical implications of reversible protein s-glutathionylation. Antioxid Redox Signal 2008; 10: 1941-1988.

15. Satoh T, Yoshioka Y. Contribution of reduced and oxidized glutathione to signals detected by magnetic resonance spectroscopy as indicators of local brain redox state. Neurosci Res 2006; 55: 34-39.

16. Ghizoni DM, Pavanati KC, Arent AM, Machado C, Faria MS, Pinto CM et al. Alterations in glutathione levels of brain structures caused by acute restraint stress and by nitric oxide synthase inhibition but not by intraspecific agonistic interaction. Behav Brain Res 2006; 166: $71-77$

17. Orlowski $M$, Meister $A$. The gamma-glutamyl cycle: a possible transport system for amino acids. Proc Natl Acad Sci USA 1970; 67: 1248-1255.

18. Meister A, Anderson ME. Glutathione. Annu Rev Biochem 1983; 52: 711-760.

19. Pias EK, Aw TY. Early redox imbalance mediates hydroperoxide-induced apoptosis in mitotic competent undifferentiated PC-12 cells. Cell Death Differ 2002; 9: 1007-1016.

20. Cheng W, Fu YX, Porres JM, Ross DA, Lei XG. Selenium-dependent cellular glutathione peroxidase protects mice against a pro-oxidant-induced oxidation of NADPH, NADH, lipids, and protein. FASEB J 1999; 13: 1467-1475

21. van Leyen K, Kim HY, Lee SR, Jin G, Arai K, Lo EH. Baicalein and 12/15-lipoxygenase in the ischemic brain. Stroke 2006; 37: 3014-3018.

22. Canals S, Casarejos MJ, de Bernardo S, Rodriguez-Martin E, Mena MA. Nitric oxide triggers the toxicity due to glutathione depletion in midbrain cultures through 12 lipoxygenase. J Biol Chem 2003; 278: 21542-21549.

23. Li $Y$, Maher $P$, Schubert $D$. A role for 12-lipoxygenase in nerve cell death caused by glutathione depletion. Neuron 1997; 19: 453-463.

24. Wang H, Li J, Follett PL, Zhang Y, Cotanche DA, Jensen FE et al. 12-Lipoxygenase plays a key role in cell death caused by glutathione depletion and arachidonic acid in rat oligodendrocytes. Eur J Neurosci 2004; 20: 2049-2058.

25. Cherubini A, Ruggiero C, Polidori MC, Mecocci P. Potential markers of oxidative stress in stroke. Free Radic Biol Med 2005; 39: 841-852.

26. Hiramatsu M, Mori A. Reduced and oxidized glutathione in brain and convulsions. Neurochem Res 1981; 6: 301-306.

27. Adams Jr JD, Klaidman LK, Odunze IN, Shen HC, Miller CA. Alzheimer's and Parkinson's disease. Brain levels of glutathione, glutathione disulfide, and vitamin E. Mol Chem Neuropathol 1991; 14: 213-226.

28. Khanna S, Roy S, Park HA, Sen CK. Regulation of c-Src activity in glutamate-induced neurodegeneration. J Biol Chem 2007; 282: 23482-23490.

29. Sen CK, Khanna S, Babior BM, Hunt TK, Ellison EC, Roy S. Oxidant-induced vascular endothelial growth factor expression in human keratinocytes and cutaneous wound healing. J Biol Chem 2002; 277: 33284-33290.

30. Reid AB, Kurten RC, McCullough SS, Brock RW, Hinson JA. Mechanisms of acetaminophen-induced hepatotoxicity: role of oxidative stress and mitochondrial permeability transition in freshly isolated mouse hepatocytes. $J$ Pharmacol Exp Ther 2005; 312: 509-516.

31. Duchen MR, Surin A, Jacobson J. Imaging mitochondrial function in intact cells. Methods Enzymol 2003; 361: 353-389.

32. Nicholls DG. Simultaneous monitoring of ionophore- and inhibitor-mediated plasma and mitochondrial membrane potential changes in cultured neurons. J Biol Chem 2006; 281: 14864-14874

33. Han D, Sen CK, Roy S, Kobayashi MS, Tritschler HJ, Packer L. Protection against glutamate-induced cytotoxicity in C6 glial cells by thiol antioxidants. Am J Physiol 1997; 273: R1771-R1778.

34. De Clerck LS, Bridts CH, Mertens AM, Moens MM, Stevens WJ. Use of fluorescent dyes in the determination of adherence of human leucocytes to endothelial cells and the effect of fluorochromes on cellular function. J Immunol Methods 1994; 172: 115-124.

35. Van Damme P, Van Hoecke A, Lambrechts D, Vanacker P, Bogaert E, van Swieten J et al. Progranulin functions as a neurotrophic factor to regulate neurite outgrowth and enhance neuronal survival. J Cell Biol 2008; 181: 37-41.

36. Beierschmitt WP, McNeish JD, Griffiths RJ, Nagahisa A, Nakane M, Amacher DE. Induction of hepatic microsomal drug-metabolizing enzymes by inhibitors of 5-lipoxygenase (5-LO): studies in rats and 5-LO knockout mice. Toxicol Sci 2001; 63: 15-21.

37. DeVries AC, Joh HD, Bernard O, Hattori K, Hurn PD, Traystman RJ et al. Social stress exacerbates stroke outcome by suppressing Bcl-2 expression. Proc Natl Acad Sci USA 2001; 98: 11824-11828

38. Li X, Blizzard KK, Zeng Z, DeVries AC, Hurn PD, McCullough LD. Chronic behavioral testing after focal ischemia in the mouse: functional recovery and the effects of gender. Exp Neurol 2004; 187: 94-104.

39. Ojha N, Roy S, Radtke J, Simonetti O, Gnyawali S, Zweier JL et al. Characterization of the structural and functional changes in the myocardium following focal ischemia-reperfusion injury. Am J Physiol Heart Circ Physiol 2008; 294: H2435-H2443. 